\title{
Spatiotemporal Responses of Astrocytes, Ramified Microglia, and Brain Macrophages to Central Neuronal Infection with Pseudorabies Virus
}

\author{
L. Rinaman, ${ }^{1}$ J. P. Card, ${ }^{2}$ and L. W. Enquist ${ }^{2}$ \\ The Medical College of Pennsylvania, Department of Anatomy and Neurobiology, Philadelphia, Pennsylvania 19129 and \\ 2DuPont Merck Pharmaceutical Company, Viral Diseases Research, Wilmington, Delaware 19880
}

We examined the responses of astrocytes, ramified microglia, and brain macrophages to CNS neuronal infection with virulent or attenuated strains of a swine alpha herpesvirus (pseudorabies virus, PRV). After PRV inoculation of the rat stomach or pancreas, the temporal course of viral replication and induced pathology of infected neurons were assessed in the dorsal motor nucleus of the vagus (DMV) and amygdala using an antiserum generated against PRV. Specific monoclonal antibodies against glial fibrillary acidic protein (GFAP), OX42, and ED1 and morphological criteria were used to classify non-neuronal cells. Both PRV strains infected DMV and motor neurons and then passed transneuronally to infect brainstem neurons that innervate the DMV. However, the onset of neuronal infection produced by the attenuated strain occurred approximately $20 \mathrm{hr}$ later than infection with the virulent strain. Animals infected with the attenuated strain also survived longer, permitting transneuronal passage of virus into forebrain areas of the visceral neuraxis.

Neuronal infection with both PRV strains produced consistent alterations in astrocytes, ramified microglia, and brain macrophages that correlated spatially and temporally with progressive stages of viral replication and neuronal pathology. Early stages of infection were characterized by increases in immunoreactivity for astrocytic GFAP and microglial OX42 that preceded overt signs of neuronal pathology. At later stages, GFAP immunoreactivity decreased dramatically in focal areas of neuronal infection while $0 \times 42$ immunoreactivity continued to increase. Subsequently, ED1-immunoreactive brain macrophages infiltrated these infected areas. Double immunocytochemical labeling demonstrated that some astrocytes and brain macrophages were immunopositive for viral antigens but ramified microglia were not. The responses of glia and brain macrophages are consistent with a proposed role in restricting extracellular spread of virus by isolating or phagocytosing infected cells. These phenomena may contribute to the specific transneuronal transport exhibited by PRV.

Received May 1, 1992; revised July 30, 1992; accepted Aug. 4, 1992.

This work was supported by DuPont Merck Pharmaceutical Co. and NRSA Grant 1F32NS08900 awarded to L.R. We are grateful to Drs. Pat Levitt, Marion Murray, and Itzhak Fischer for their insightful comments on earlier versions of the manuscript. Mary Whealy, Alan Robbins, Henry Pautler, and Joan Dubin provided expert assistance in various phases of these studies.

Correspondence should be addressed to J. P. Card, Department of Behavioral Neuroscience, 446 Crawford Hall, University of Pittsburgh, Pittsburgh, PA 15260. Copyright (C) 1993 Society for Neuroscience $0270-6474 / 93 / 130685-18 \$ 05.00 / 0$
IKey words: Herpesvirus, dorsal motor vagus, amygdala, glia, macrophages, immunohistochemistry]

The use of live alpha herpesviruses for transneuronal tracing of neural circuits has gained considerable attention in recent years (reviewed by Kuypers and Ugolini, 1989). The utility of this method is based upon the affinity of herpesviruses for neurons (neurotropism), the assumption that interneuronal transfer of virus in the brain occurs only through sites of synaptic contact, and the fact that the continuous replication of virus within infected neurons enables easy detection with immunocytochemical methods. Support for the contention that herpesviruses preferentially pass through synapses is evident in numerous investigations demonstrating unique, projection-specific patterns of neuronal infection following injection of virus at different sites (Kristensson et al. 1971, 1974, 1978, 1982; Cook and Stevens, 1973; Field and Hill, 1974; Bak et al., 1977; Martin and Dolivo, 1983; Rouiller et al., 1986, 1989; Margolis et al., 1987, 1989; Stroop and Schaefer, 1987; Ugolini et al., 1987, 1989; McLean et al., 1989; Norgren and Lehman, 1989; Strack et al., 1989a,b; Card et al., 1990, 1991, 1992; Strack and Loewy, 1990; Stroop et al., 1990; Blessing et al., 1991; Zemanick et al., 1991; RottoPercelay et al., 1992; Yu-Wen et al., 1992). However, herpesviruses also induce pathological changes in infected neurons that may lead to neuronal death (Stevens, 1991). In particular, the demonstration of viral antigens within glia located adjacent to chronically infected neurons and their processes (Ugolini et al., 1987; Strack et al., 1989a,b; Card et al., 1990, 1991, 1992; Strack and Loewy, 1990; Blessing et al., 1991) raises the possibility that CNS transport of herpesvirus may proceed through nonsynaptic routes.

The extent and outcome of CNS herpesvirus infection depend on a variety of factors including the virulence of the virus, the quantity of infectious agent injected, and the site of inoculation. Virulence is a complex phenotype that involves the ability of the virus to infect and replicate in the CNS, as well as the extent of the host's response to the infection (reviewed by Stevens, 1991). Two herpesviruscs commonly uscd for ncuronal tract tracing are the human herpesvirus, herpes simplex virus type 1 (HSV-1), and the swine herpesvirus, pseudorabies virus (PRV). The extent of glial infection varies substantially among different species and strains of herpesvirus, with the most virulent strains producing robust neuronal infection accompanied by pronounced glial infection (Ugolini et al., 1987; Norgren and Lehman, 1989; Card et al., 1990, 1992; Strack and Loewy, 1990; Blessing et al., 1991). However, even very virulent strains of 
virus infect neurons in a circuit-specific fashion that is consistent with transneuronal passage across synapses, even in the presence of extensive glial infection (Card et al., 1990, 1991, 1992; Blessing et al., 1991). In previous work we demonstrated that a virulent strain of PRV (PRV-Becker; Becker, 1967) injected into the stomach wall infects parasympathetic neurons in the dorsal motor nucleus of the vagus (DMV) and subsequently infects other brainstem neurons known to innervate the DMV (Card et al., 1990). Although the initial infection is confined to neurons, at later stages of viral replication, non-neuronal cells located in the immediate vicinity of the most severely infected neurons and their processes become positive for viral antigens. However, there is no evidence of subsequent viral passage from these non-neuronal cells. More recently, we have examined the transport of an attenuated strain of PRV (PRV-Bartha; Bartha, 1961) through vagal pathways (Miselis et al., 1991; Sternini et al., 1991). Because of the less virulent nature of PRV-Bartha, infected animals live longer, enabling us to follow the virus through a multisynaptic circuit extending into the forebrain. In addition, neuronal pathology is delayed and glial infection occurs only at long postinjection intervals.

The anatomical precision of viral passage through defined neural circuits continues to provide the best evidence for specific transsynaptic transport of alpha herpesviruses. However, the involvement of non-neuronal cells in CNS infection requires further examination. The systematic, progressive viral replication and transneuronal transport that makes PRV valuable for tract tracing also offers an excellent opportunity to study temporal and spatial aspects of the non-neuronal response to infection. As noted above, astrocytes have been implicated in central PRV infection, but the involvement of other types of glia and phagocytes in determining the outcome of central viral transport is unclear. The present investigation uses specific antibodies and morphological criteria to characterize the responses of astrocytes, ramified microglia, and brain macrophages to progressive infection of multisynaptic pathways with PRV-Becker (virulent) or PRV-Bartha (attenuated). The data reveal spatially and temporally organized responses of these non-neuronal cells that are strictly correlated with the degree of neuronal infection produced by each PRV strain. The characteristics of this response support the hypothesis that glia and macrophages isolate the infection by restricting indiscriminate extracellular spread of virus, thereby facilitating the specific transport of PRV exclusively through synaptically linked neural circuits.

\section{Materials and Methods}

Animals. Adult male $(n=35)$ and female $(n=7)$ Sprague-Dawley rats $(250-350 \mathrm{gm})$ were used. Rats were maintained in a standardized photoperiod (12 hr light; light on at 0600$)$ and had free access to food and water. All experimental protocols were approved by the local Animal Welfare Committee and conformed to regulations stipulated in the $N I H$ Guide for the Care and Use of Laboratory Animals, HHS publication no. (NIH) 88-8395. Experimental procedures were conducted on rats anesthetized with either Nembutal $(30 \mathrm{mg} / \mathrm{kg}$, i.p.) or a mixture of ketamine and xylazine $(60 \mathrm{mg} / \mathrm{kg}$ ketamine, $7 \mathrm{mg} / \mathrm{kg}$ xylazine, i.m.). Rats were carefully monitored following virus injection, and the longestsurviving animals were killed when they displayed adverse symptoms of infection.

Virus and injection procedures. Two strains of PRV were used: PRVBecker, a virulent strain (Recker, 1967), and PRV-Bartha, an attenuated vaccine strain (Bartha, 1961). The titer of PRV-Becker used was $6 \times$ $10^{8} \mathrm{pfu} / \mathrm{ml}$, and the titer for PRV-Bartha was $5 \times 10^{8} \mathrm{pfu} / \mathrm{ml}$. Information on the preparation, characterization, genetics, and use of these strains in the CNS has been published previously (Robbins et al., 1989; Card et al., 1990, 1991, 1992). PRV-Becker produces robust neuronal infection with extensive glial involvement at long survival times. Rats injected with PRV-Becker generally exhibit oral-nasal excretions, anorexia, adipsia, and progressive hunched immobility within $55 \mathrm{hr}$ of injection, and most do not survive beyond $65 \mathrm{hr}$ (Card et al., 1990, 1992). In contrast, rats injected with PRV-Bartha rarely show any overt symptoms of infection before $100 \mathrm{hr}$ postinjection. Depending on the virus titer and the route of inoculation, some animals survive as long as $6 \mathrm{~d}$ after PRV-Bartha injection (Strack et al., 1989a,b; Card et al., 1992).

All experimental manipulations involving PRV were conducted in a laboratory equipped for Biosafety Level 2 studies. Details regarding our operation of this laboratory and precautions used in handling the virus have been published previously (Card et al., 1990). Rats were injected with virus ( $n=8$, PRV-Becker; $n=20$, PRV-Bartha) or served as uninjected controls for normal immunocytochemical analysis of nonneuronal cells $(n=14)$. Each strain of virus was injected either into the antral region of the ventral stomach wall $(n=9)$ or into the splenic lobe of the pancreas $(n=19)$. In each case, laparotomy was performed on anesthetized rats, the stomach and attached splenic pancreas were gently pulled through the peritoneal incision and held in place with gauze soaked in sterile saline, and a total volume of $2-5 \mu 1$ of virus was injected at three or four sites using a $10 \mu \mathrm{l}$ Hamilton syringe. After swabbing the injection sites with clean gauze, the viscera were returned to the abdominal cavity, peritoneal and skin incisions were sutured in two layers, and the animal was returned to its cage. Animals were isolated in the Biosafety laboratory throughout the course of each experiment.

Tissue preparation. After survival times of $24-110 \mathrm{hr}$, anesthetized rats were perfused transcardially with saline followed by $4 \%$ paraformaldehyde containing lysine and sodium meta-periodate (McLean and Nakane, 1974). The brain was then removed, postfixed for $10-15 \mathrm{hr}$, rinsed in several changes of $0.1 \mathrm{~m}$ phosphate buffer $(\mathrm{pH} 7.4)$ for $8-10$ $\mathrm{hr}$, and cryoprotected for at least $60 \mathrm{hr}$ by immersion in $30 \%$ buffered sucrose (all at $4^{\circ} \mathrm{C}$ ). Coronal tissue sections were cut with a freezing microtome ( $35-40 \mu \mathrm{m}$ sections) for free-floating immunoperoxidase histochemistry. In addition, some medullary tissue sections were cut with a cryostat ( $10 \mu \mathrm{m}$ sections) for immunofluorescence localizations. Some sections were stained with cresyl violet for cytoarchitectural analysis using standard procedures.

Antisera. A rabbit polyclonal antiscrum (R134, diluted 1:1000) generated against an acetone-inactivated form of PRV-Becker was used to localize the virus in tissue sections. R134 recognizes major viral membrane and capsid proteins (Card et al., 1990). Astrocytes were identified with a monoclonal antibody (IgG1; Chemicon International Inc., Temecula, CA; diluted 1:10,000) raised against homogeneous glial fibrillary acidic protein (GFAP) isolated from bovine spinal cord. GFAP is the major protein constituent of cell-specific intermediate filaments in normal and reactive astrocytes (Eng, 1980; Lazarides, 1982). To identify microglia and brain macrophages, we used the morphological and immunocytochemical criteria recently defined by Milligan et al. (199 la,b; see also Rinaman et al., 1991). Accordingly, the monoclonal antibodies OX42 (IgG2a; Bioproducts for Science, Indianapolis, IN; diluted 1:1000) and EDI (IgG1; Bioproducts for Science; diluted 1:150) were used. $\mathrm{OX} 42$, generated against rat peritoneal macrophages, recognizes an antigen associated with the complement $\mathrm{C} 3 \mathrm{bi}$ receptor. $\mathrm{C} 3 \mathrm{bi}$ is expressed by neutrophils, monocytes, macrophages, and ramified and amoeboid microglia (Perry et al., 1985; Robinson et al., 1986). In the normal adult rat CNS, OX42 labels the cell membranes of ramified microglia, amoeboid microglia (also known as resident brain macrophages) in the circumventricular organs, scattered flattened perivascular cells, and round cells in the meninges and ventricular lining. The EDI antibody recognizes an unidentified cytoplasmic antigen that is unique to all phagocytic cells of monocyte/macrophage origin (Dijkstra et al., 1985). In the normal adult rat CNS, ED1 recognizes all OX42-positive cells, with one notable exception: ED1 does not label ramified microglia (Sminia et al., 1987; Milligan et al., 1991a,b; Rinaman et al., 1991). Although some types of CNS damage induce EDI immunoreactivity within subsets of activated ramified microglia, these cells are still recognized as microglia because their morphology is maintained (Milligan et al., 1991b), even when they are actively phagocytic (Rinaman et al., 1991).

Immunohistochemical methods. All antibodies were diluted in Blotto (0.1 м phosphate-buffered saline, $\mathrm{pH} 7.4$, containing $4 \%$ nonfat dry milk and $0.3 \%$ Triton X-100). For immunoperoxidase labeling, floating sections were incubated in primary antiserum with gentle agitation overnight at room temperature or for $2448 \mathrm{hr}$ at $4^{\circ} \mathrm{C}$. Sections were then rinsed in several changes of phosphate buffer and incubated in HRPtagged secondary antisera (FisherBiotech, Pittsburgh, PA; 1:100 dilu- 
tion) for $2 \mathrm{hr}$ at room temperature, rinsed thoroughly in several changes of phosphate buffer, and enzymatically reacted in a solution of $0.5 \%$ diaminobenzidine (DAB) containing $0.01 \% \mathrm{H}_{2} \mathrm{O}_{2}$. In some cases the peroxidase reaction product was intensified by adding $0.5 \%$ nickel ammonium sulfate to the DAB reaction mixture (Adams, 1981), but qualitative comparisons of immunostaining patterns were always made between sections treated by the same peroxidase method. The peroxidase reaction was terminated by several buffer rinses. Sections were then mounted on gelatin-coated slides, dried overnight, dehydrated with ethanol, cleared in xylene, and coverslipped with Histomount (National Diagnostics, Manville, NJ) for light microscopic examination.

For immunofluorescence, slide-mounted cryostat sections were ringed with rubber cement, covered with primary antibody, and incubated overnight at room temperature in a sealed humidified box. In most cases, two of the primary antibodies were combined in a single incubation for double antigen detection in the same tissue section. After primary antibody incubation, slides were rinsed in several changes of buffer and then incubated for $2 \mathrm{hr}$ at room temperature in goat antirabbit or goat anti-mouse isotype-specific secondary antisera (FisherBiotech; 1:50 dilution) tagged with fluorescein isothiocyanate or tetramethylrhodamine isothiocyanate. For double labeling, two isotypespecific, secondary antibodies tagged with different fluorophors were combined in a single incubation. Slides were then rinsed in several changes of buffer and coverslipped with Gelmount (Biomeda, Foster City, CA) for fluorescence microscopic examination.

The specificity of peroxidase and fluorescent immunolabeling was verified by incubation of tissue sections in each primary antibody followed by incubation with inappropriate isotype-specific secondary antibodies. In no case did this result in cell labeling.

\section{Results}

Injection of either PRV-Becker or PRV-Bartha into the stomach wall or pancreas always resulted in uptake, retrograde transport, and subsequent viral replication in DMV motor neurons, followed by specific transneuronal viral passage within defined central neural circuits. Virus was also transported by sensory neurons in the nodose and dorsal root ganglia and through sympathetic spinal cord circuits (see Miselis et al., 1991; Sternini et al., 1991), but the present article focuses on central infection in the vagal motor and sensory nuclei (Fig. $1 A$ ) and the central nucleus of the amygdala (CeA; Fig. $1 B$ ).

Postsynaptic enteric neurons in the ventral stomach wall are innervated primarily by motor neurons in the left DMV (Shapiro and Miselis, 1985), while neurons in the splenic portion of the pancreas are innervated primarily by motor neurons in the right DMV (Rinaman and Miselis, 1987). The initial distribution of infected DMV motor neurons seen in this study was entirely consistent with this organization. Subsequent infection of motor neurons in the opposite DMV also occurred following both injection paradigms, an observation that may be attributed to transneuronal transport within local circuits of the DMV and nucleus of the solitary tract (NST), or to viral replication and transport within peripheral enteric neurons and subsequently to additional DMV neurons (Sternini et al., 1991). No differences in the temporal onset, extent of neuronal infection, or the reaction of non-neuronal cells were observed between stomachinjected or pancreas-injected rats. The present results, therefore, are described without reference to which organ was injected. However, this information is included in the figure captions.

Temporal aspects of viral replication and pathogenesis in neurons

\section{$P R V$-Becker}

The time course and extent of central neuronal infection following stomach injection with PRV-Becker have been described in detail (Card et al., 1990), and the present results are similar. We defined three stages of infection of DMV neurons. Rb134
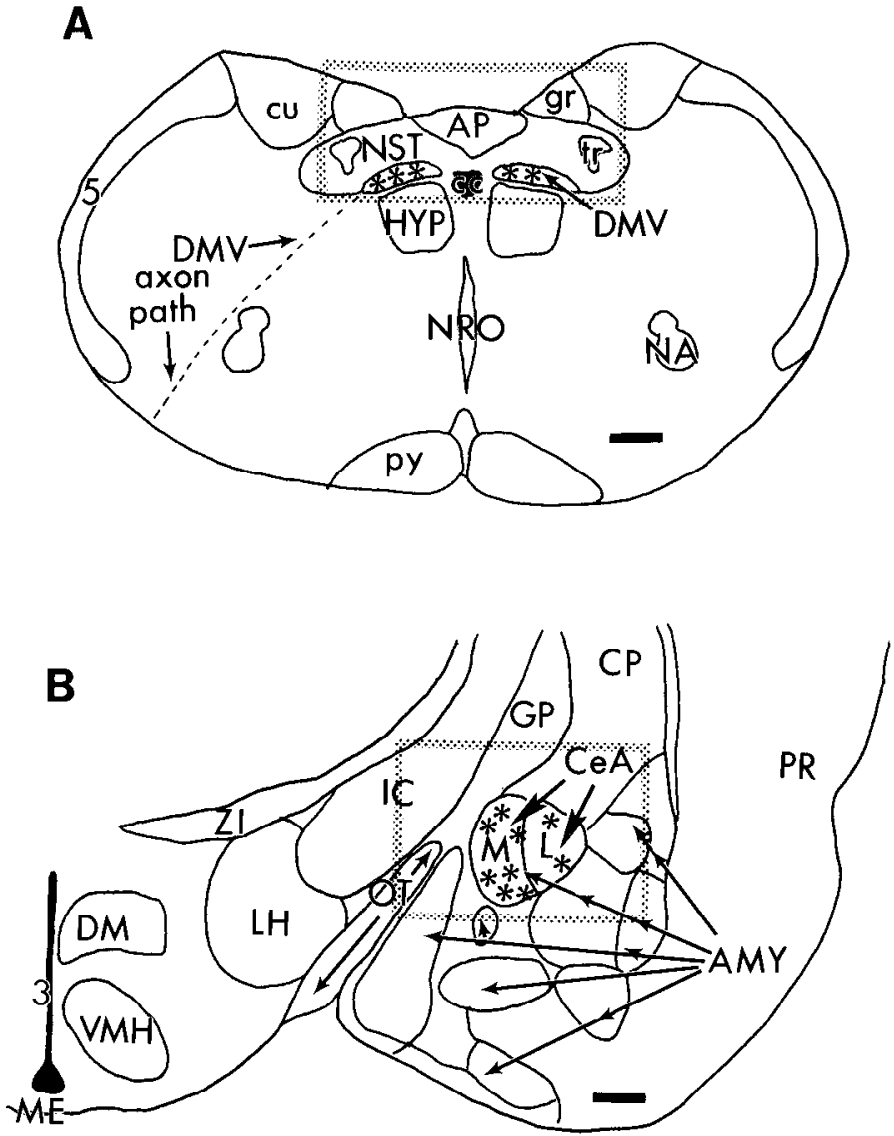

Figure 1. The schematic diagrams are of coronal sections through the brainstem at the level of the DMV/NST $(A)$ and through an intermediate level of the amygdaloid complex $(B)$. In both figures, the stippled box designates the area illustrated in subscquent photomicrographs. Asterisks represent the location of neurons in the DMV $(A)$ and amygdala $(B)$ that were infected by peripheral injection and transneuronal transport of PRV. $A M Y$, amygdala nuclei; $A P$, area postrema; $c c$, central canal; $C e A$, central nucleus of the amygdala $(M$, medial; $L$, lateral $\mathrm{CeA})$; $C P$, caudate putamen; $c u$, cuneate fasciculus; $D M$, dorsomedial nucleus of the hypothalamus; $D M V$, dorsal motor nucleus of the vagas; $G P$, globus pallidus; $g r$, gracile fasciculus; $H Y P$, hypoglossal nucleus; $I C$, internal capsule; $L H$, lateral hypothalamic area; $M E$, median eminence; $N A$, nucleus ambiguus; $N R O$, nucleus raphe obscurus; $N S T$, nucleus of solitary tract; $O T$, optic tract; $P R$, perirhinal cortex; $p y$, pyramidal tract; $t r$, tractus solitarius; $V M H$, ventromedial hypothalamus; $Z I$, zona incerta; 3, third ventricle; 5 , trigeminal tract. Scale bars, $500 \mu \mathrm{m}$. Both figures were adapted from Paxinos and Watson, 1986.

(viral antigens) immunoreactivity was first observed in DMV motor neurons approximately $30 \mathrm{hr}$ following visceral inoculation (early stage of infection). Between 50 and $60 \mathrm{hr}$ postinjection (intermediate stage of infection), the number of viruspositive DMV motor neurons was much increased, but their distribution was still essentially unilateral (Fig. 2A). Infected second-order neurons were also apparent in the medial NST (Fig. $2 A$ ). At survival times extending from 60 to $75 \mathrm{hr}$ (late stage of infection), PRV-Becker-infected neurons became apparent in the area postrema (AP) and other caudal medullary nuclei known to innervate the dorsal vagal complex (i.e., raphe obscurus, raphe pallidus, paratrigeminal nucleus). However, we never observed any immunoreactive neurons in either the midbrain or forebrain, or in medullary areas lacking a known projection to the vagal nuclei. This is best illustrated by the complete absence of infected cells within the directly adjacent 

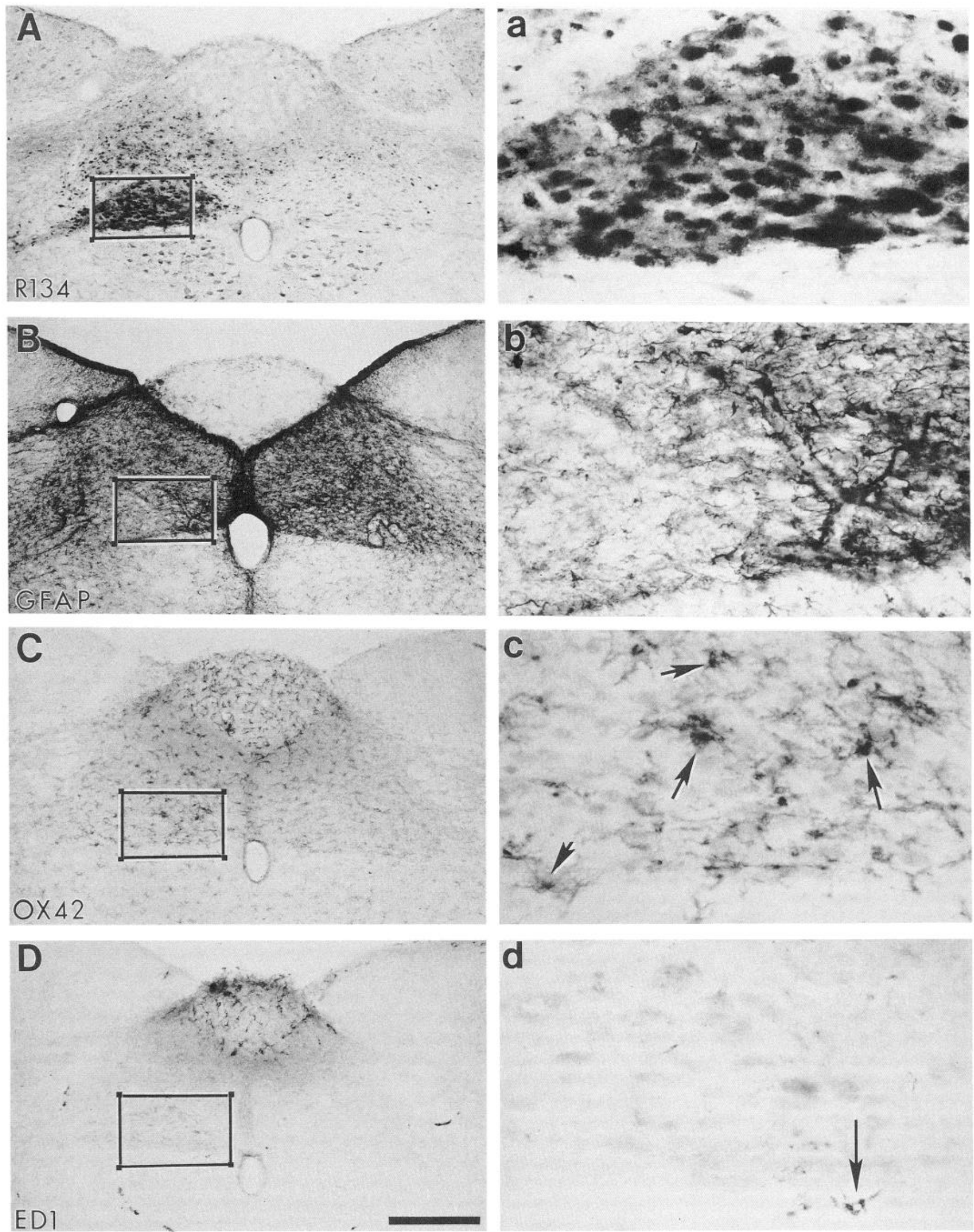

Figure 2. Photomicrographs of adjacent sections through the caudal brainstem of an animal killed $53 \mathrm{hr}$ after injection of PRV-Becker into the ventral wall of the stomach. Left and right are as they appear. $A$ illustrates the distribution of neurons in the DMV and NST exhibiting R134 (viral) immunoreactivity (the nickel intensification procedure produced some background staining that is apparent in the hypoglossal nucleus and other areas in this particular photograph, but these cells are not infected). The distribution of GFAP-immunoreactive astrocytes, OX42-immunoreactive microglia, and EDl-immunoreactive brain macrophages is shown in $B, C$, and $D$, respectively. The boxed areas in $A-D$ are shown at higher magnification in $a-d$. Arrows in $c$ and $d$ point out individual microganglia and macrophages, respectively. Scale bar, $500 \mu \mathrm{m}$ for $A-D . a-d$ are $4.5 \times$ the magnification of $A-D$. 
hypoglossal nuclei and the gracile/cuneate area, even at the longest postinjection survival times (Fig. $2 A, a$ ).

Viral immunoreactivity in PRV-Becker-infected neurons was present in both the nuclei and cytoplasm. At early stages of viral replication, immunoreactivity was most dense in the nucleus, and was either absent or light in the cytoplasm. With advancing postinjection survival times and continued viral replication, viral immunoreactivity became dense throughout the perikarya and sometimes extended into primary dendrites. This is consistent with the fact that our polyclonal R134 antiserum recognizes viral epitopes specific to both the viral capsid, which is assembled in the cell nucleus, and the viral envelope, which is applied to the capsid in the cytoplasm (see Whealy et al., 1991, for a description of PRV replication and assembly). Neurons in early stages of viral replication ( $\leq 50 \mathrm{hr}$ postinjection) did not appear compromised. Their cell nuclei remained oval and their perikarya and proximal dendrites appeared normal. At survival times greater than $50 \mathrm{hr}$, the conformation of the nuclei and perikarya of many chronically infected cells was irregular (Fig. $2 a$ ). At the longest survival times (up to $75 \mathrm{hr}$ ) the membrane integrity of some severely infected neurons appeared to be lost, but there was no indication of virus diffusion from the immediate vicinity of infected neurons.

\section{PRV-Bartha}

Infection of DMV motor neurons following injection of the attenuated strain of PRV was delayed compared to that produced by injection of PRV-Becker. Once again, three stages of PRV infection (early, intermediate, and late) were defined based on the appearance of viral immunoreactivity and the morphology of infected neurons. The first appearance of virus immunoreactivity occurred in scattered DMV motor neurons 50$60 \mathrm{hr}$ after PRV-Bartha inoculation (early stage of infection), but the number of infected neurons was substantially fewer than the number of PRV-Becker infected neurons at the same survival time. By $70 \mathrm{hr}$ (intermediate stage of infection), the distribution of infected neurons was similar to that seen in the latest stage of PRV-Becker infection; that is, large numbers of infected neurons were present in the DMV, and second-order infected neurons were present in the NST, AP, and other medullary nuclei that innervate the vagal nuclei. At $90 \mathrm{hr}$ and longer postinjection (late stage of infection), the density of infected medullary neurons was increased and some of the chronically infected cells exhibited advanced pathology (Figs. 3A, 4A).

With postinjection survival times of $80 \mathrm{hr}$ and longer, infected neurons were also present in more rostral regions of the visceral neuraxis that are known to project to the dorsal vagal complex (i.e., amygdala, hypothalamus, insular cortex). Two studies providing complete descriptions of the pattern of infectivity resulting from injection of PRV-Bartha into the stomach or pancreas are in preparation and have been published in abstract form (Miselis et al., 1991; Sternini et al., 1991). For the present article, the $\mathrm{CeA}$ was selected as a representative nucleus to correlate transneuronal viral labeling with the response of nonneuronal cells (Fig. 5). The medial division of the CeA has monosynaptic descending projections to the dorsal vagal complex (Schwaber et al., 1982; Gray, 1983; Higgins and Schwaber, 1983). At $85 \mathrm{hr}$ after PRV-Bartha injection, a few scattered infected neurons were observed in the medial CeA ipsilateral to the initially infected DMV. The number of immunoreactive neurons in the medial CeA increased progressively through 100 hr survival, at which time infected neurons first became apparent in the lateral subdivision of the $\mathrm{CcA}$. By $110 \mathrm{hr}$ survival (the longest time examined), substantial numbers of infected neurons, some of which exhibited pathological vacuolizations, were present in both subdivisions (Fig. 5A,a).

Neurons infected with PRV-Bartha displayed the same sequential intracellular appearance of viral immunoreactivity observed for PRV-Becker, in that nuclear labeling was observed first, followed by increased cytoplasmic labeling. However, the pathological consequences of PRV-Bartha infection were less severe and occurred over a more protracted time course. DMV motor neurons infected with PRV-Bartha appeared normal through $80 \mathrm{hr}$ postinjection, although some appeared compromised by $90 \mathrm{hr}$ or longer (Figs. $3 a, 4 a$ ). Neurons at earlier stages of PRV-Bartha infection often contained viral immunoreactivity extending through their proximal, secondary, and even tertiary dendrites. In contrast, neurons infected with PRV-Becker did not display such extensive dendritic labeling.

\section{Non-neuronal response to PRV neuronal infection}

For each viral strain, the temporally separated onset of neuronal infection in the DMV/NST and in the two CeA subdivisions provided an excellent model for relating the response of glia and macrophages to different stages of neuronal infectivity. It is important to note that following injection of either PRV strain, the progressive changes in astrocytes, microglia, and brain macrophages observed in the DMV and amygdala occurred when infected neurons in these nuclei reached approximately the same points of viral replication. In addition, the initial glial responses preceded any changes in neuronal morphology that could be defined as pathological.

\section{GFAP-immunoreactive astrocytes}

Normal distribution. In normal, uninfected rats, the distribution and staining intensity of GFAP-immunoreactive astrocytes were higher in the DMV and NST than in adjacent areas of the medulla (Fig. $6 \mathrm{~A}$ ). Particularly dense concentrations of GFAPimmunoreactive processes were noted along the midline between the left and right DMV, and along the medial border of the NST with the AP. However, the AP contained substantially fewer GFAP-positive profiles than either the DMV or NST. The high density of GFAP staining in the DMV and NST was primarily due to the larger size and more extended process network of individual astrocytes in these nuclei as compared to adjacent medullary areas (Fig. 6a). The large, irregular perikarya of astrocytes in the DMV and NST gave rise to numerous ramifying processes that were particularly dense adjacent to blood vessels.

Astrocytic response to neuronal infection. GFAP-immunorcactivc astrocytcs cxhibitcd a dramatic response to neurons infected with either strain of PRV. Following PRV-Becker injection, the early stage of viral replication in DMV motor neurons (30-50 hr postinjection, $n=4$ ) was accompanied by a marked bilateral increase in GFAP immunoreactivity, implying hypertrophy and/or hyperplasia of resident astrocytes (compare DMV/NST in Fig. $2 B$ with Fig. $6 A$ ). An equivalent astrocytic response took longer than $50 \mathrm{hr}$ after injection of PRV-Bartha $(n=7)$, a difference that correlated with the delayed infectivity of DMV neurons. The initial bilateral increase in GFAP immunoreactivity following injection of both PRV strains included areas of the DMV/NST in which viral immunoreactivity was not yet present (see Discussion).

Despite the initial bilateral hypertrophy of GFAP-immunoreactive astrocytes, a dramatic and very focal decrease in GFAP staining subsequently occurred in areas containing severely infected neurons in both PRV-Becker $(n=4)$ and PRV-Bartha ( $n$ 
A

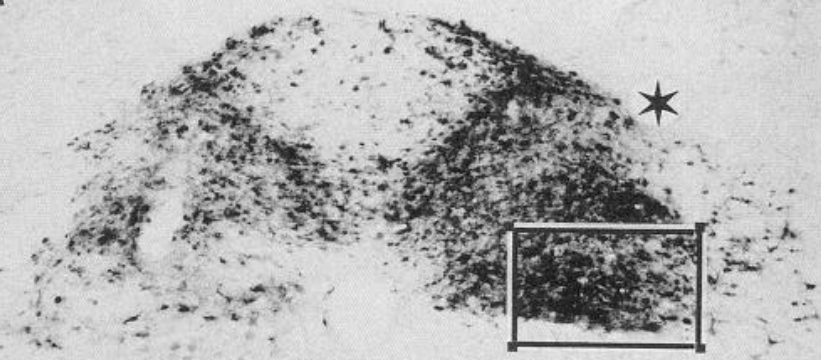

R134
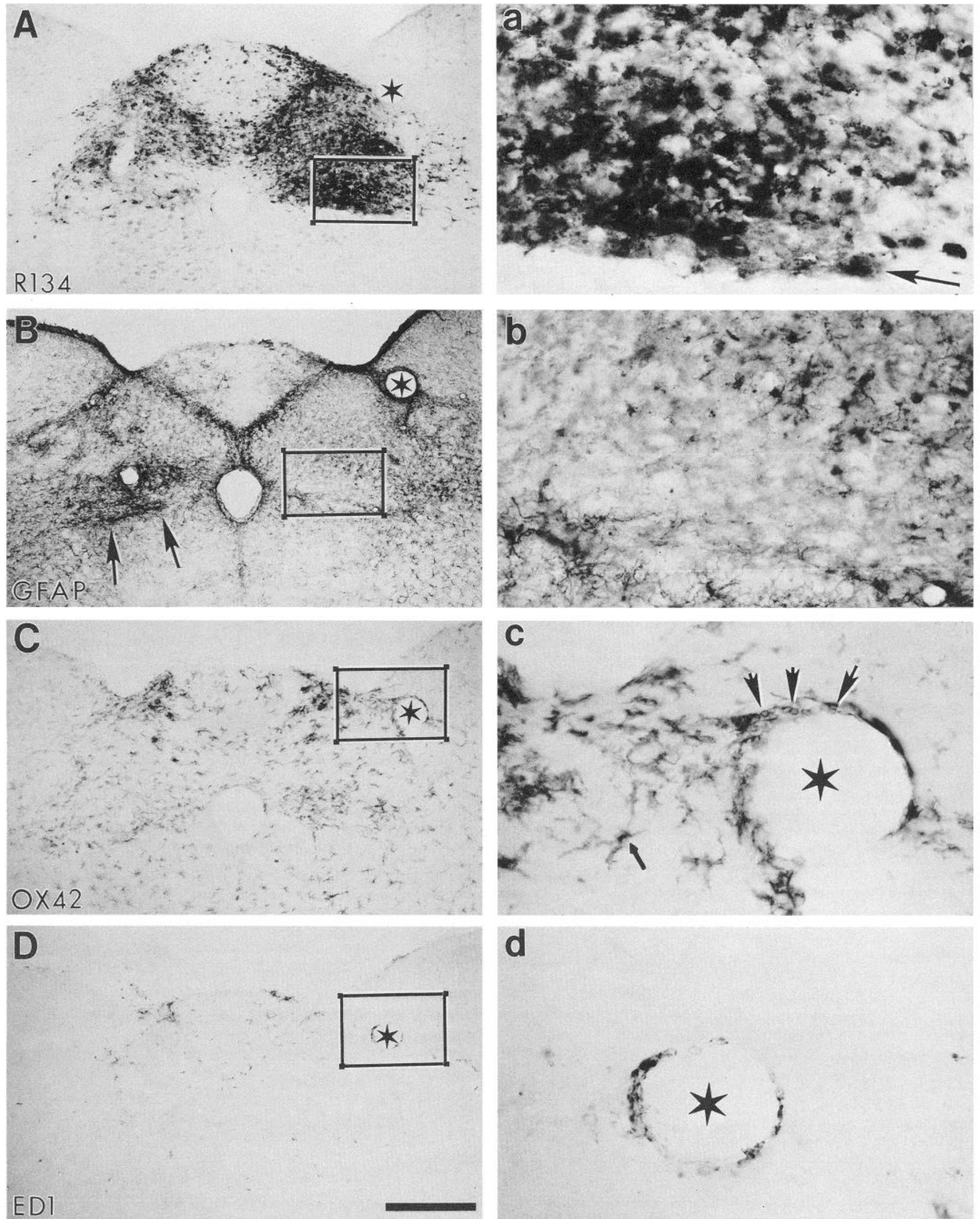

Figure 3. Photomicrographs of adjacent sections through the caudal brainstem of an animal killed $90 \mathrm{hr}$ after injection of PRV-Bartha into the splenic pancreas. Left and right are as they appear. $A$ illustrates the distribution of neurons in the DMV, NST, and AP exhibiting R134 (viral) immunoreactivity. The arrow in $a$ points to an infected neuron that appears morphologically compromised. The distribution of GFAP-immunoreactive astrocytes, OX42-immunoreactive microglia, and ED1-immunoreactive brain macrophages is shown in $B$, $C$, and $D$, respectively. In addition to microglia, round macrophages positive for OX $42(c)$ and ED1 $(d)$ appear, primarily concentrated around blood vessels $($ arrows in $c)$. In $A-D$, the same blood vessel is indicated by an asterisk. The boxed areas in $A-D$ are shown at higher magnification in $a-d$. Scale bar, $500 \mu \mathrm{m}$ for $A-D . a-d$ are $4.5 \times$ the magnification of $A-D$. 

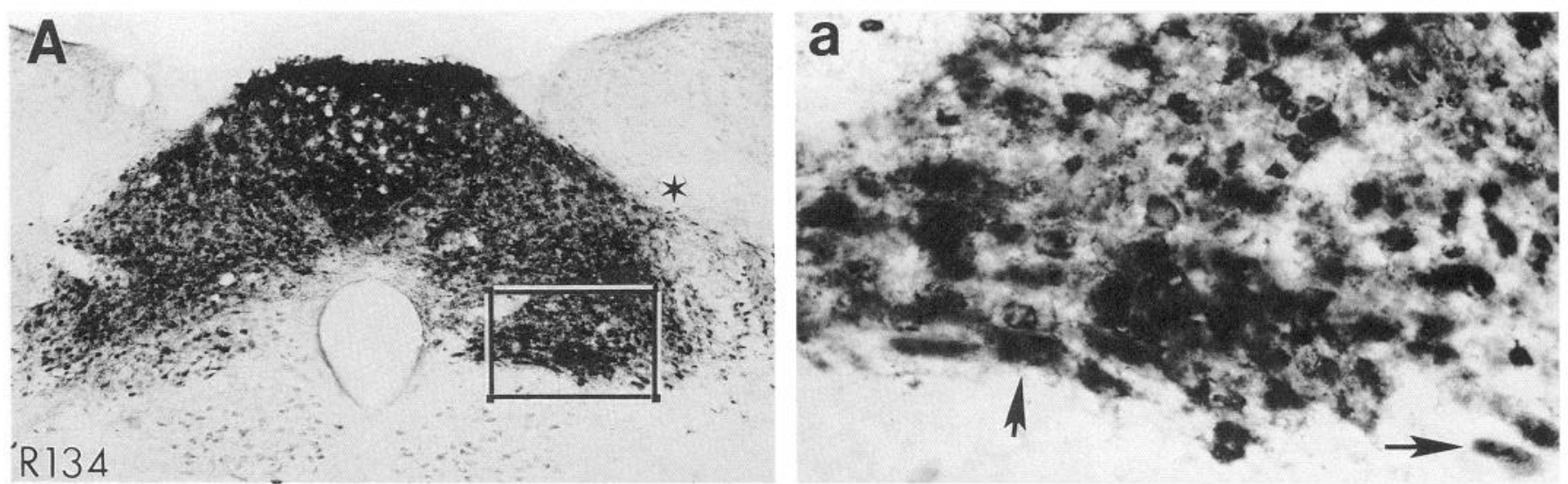

R134
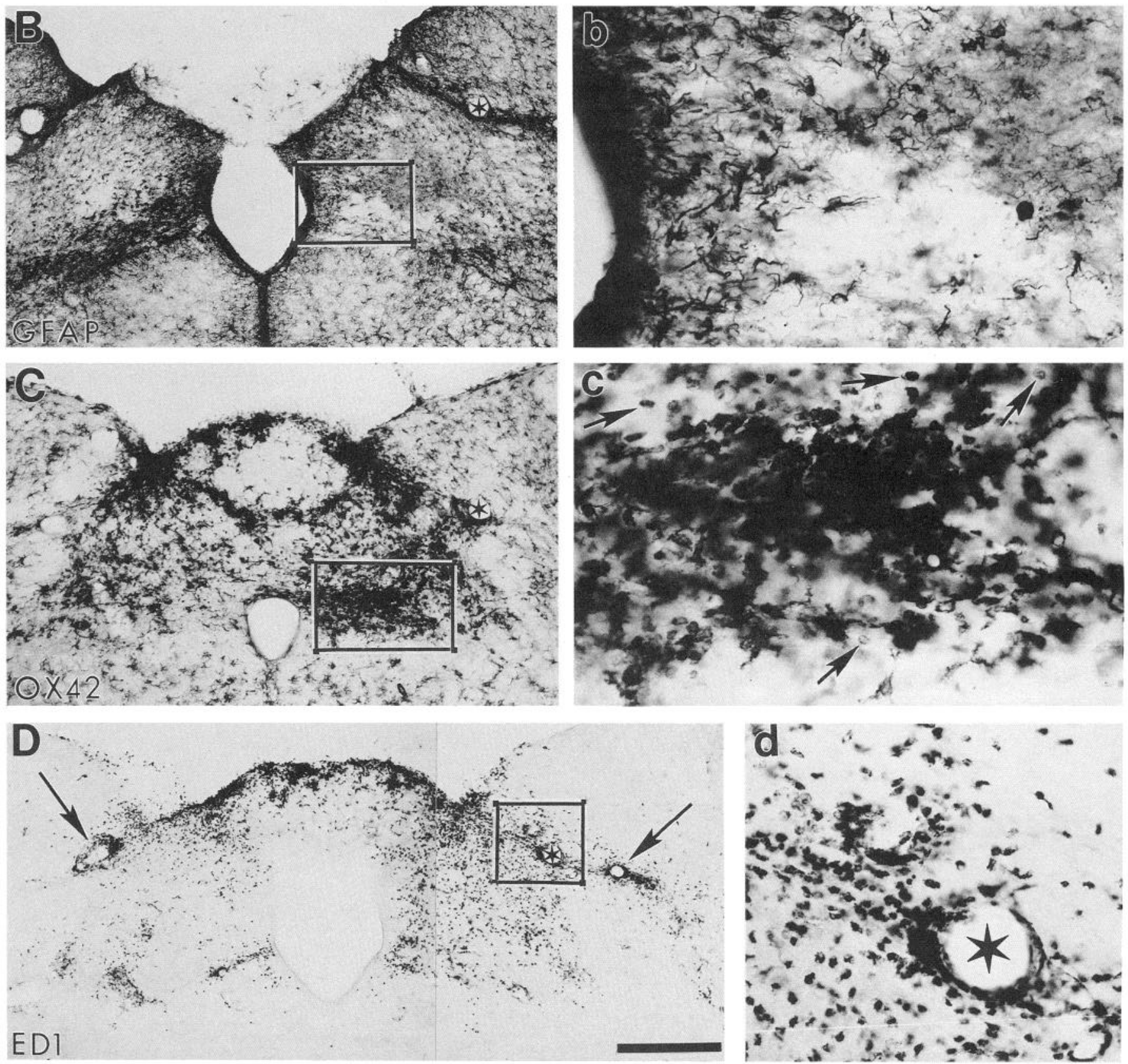

Figure 4. Photomicrographs of adjacent sections through the caudal brainstem of an animal killed $110 \mathrm{hr}$ after injection of PRV-Bartha into the splenic pancreas. Left and right are as they appear. $A$ illustrates the distribution of neurons in the DMV, NST, and AP exhibiting R134 (viral) immunoreactivity. The arrows in $a$ point to infected neurons that appear morphologically compromised. The distribution of GFAP-immunoreactive astrocytes, OX 42-immunoreactive microglia, and ED1-immunoreactive brain macrophages is shown in $B, C$, and $D$, respectively. Massive infiltration of round macrophages positive for OX42 (arrows in $c$ ) and EDI $(d)$ is apparent. In $A-D$ and $d$, the same blood vessel is indicated by an asterisk. Arrows in $D$ indicate large blood vessels encircled by ED1-positive macrophages. The boxed areas in $A-D$ are shown at higher magnification in $a-$ $d$. Scale bar, $500 \mu \mathrm{m}$ for $A-D$. $a-d$ are $4.5 \times$ the magnification of $A-D$. 

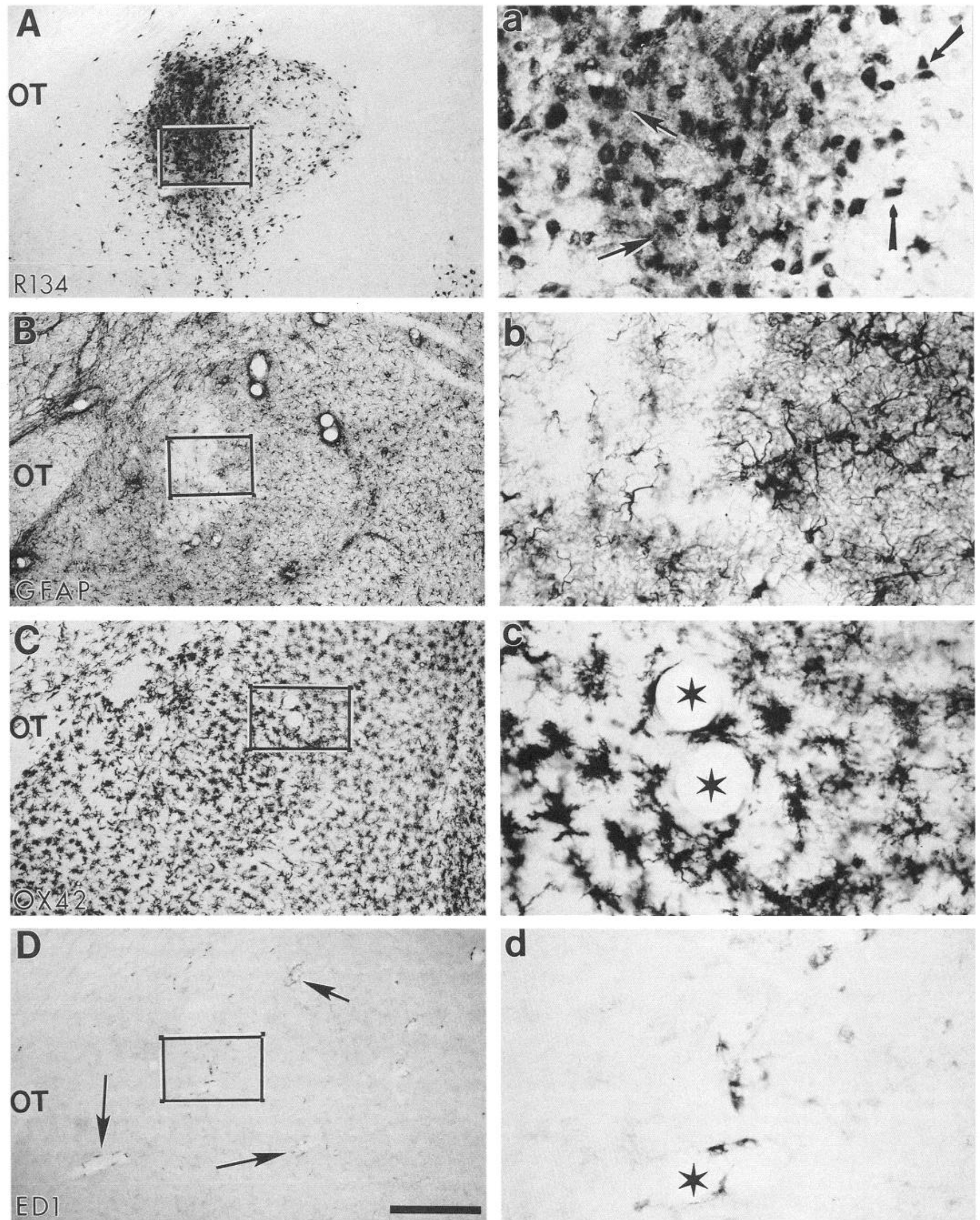

d
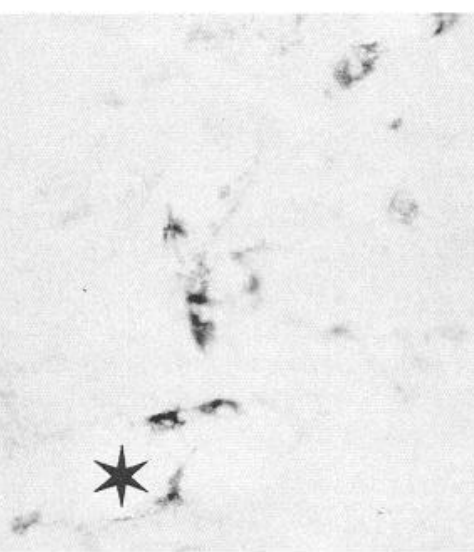

Figure 5. The distribution of R134 (virus-infected) neurons (A), GFAP-positive astrocytes $(B)$, OX42-positive microglia ( $C$ ), and ED1-positive brain macrophages $(D)$ in the CeA $110 \mathrm{hr}$ after injection of PRV-Bartha into the splenic pancreas. Some of the infected neurons in the medial CeA appear pathological (large arrows in $a$ ), but later-infected neurons in the lateral CeA do not (small arrows in $a$ ). Arrows in $D$ point out blood vessels ringed by ED1-positive macrophages. Asterisks in $c$ and $d$ indicate blood vessels. Photographs on the right $(a-d)$ correspond to the indicated boxed areas in $A-D$. Scale bar, $500 \mu \mathrm{m}$ for $A-D . a-d$ are $4.5 \times$ the magnification of $A-D$. 

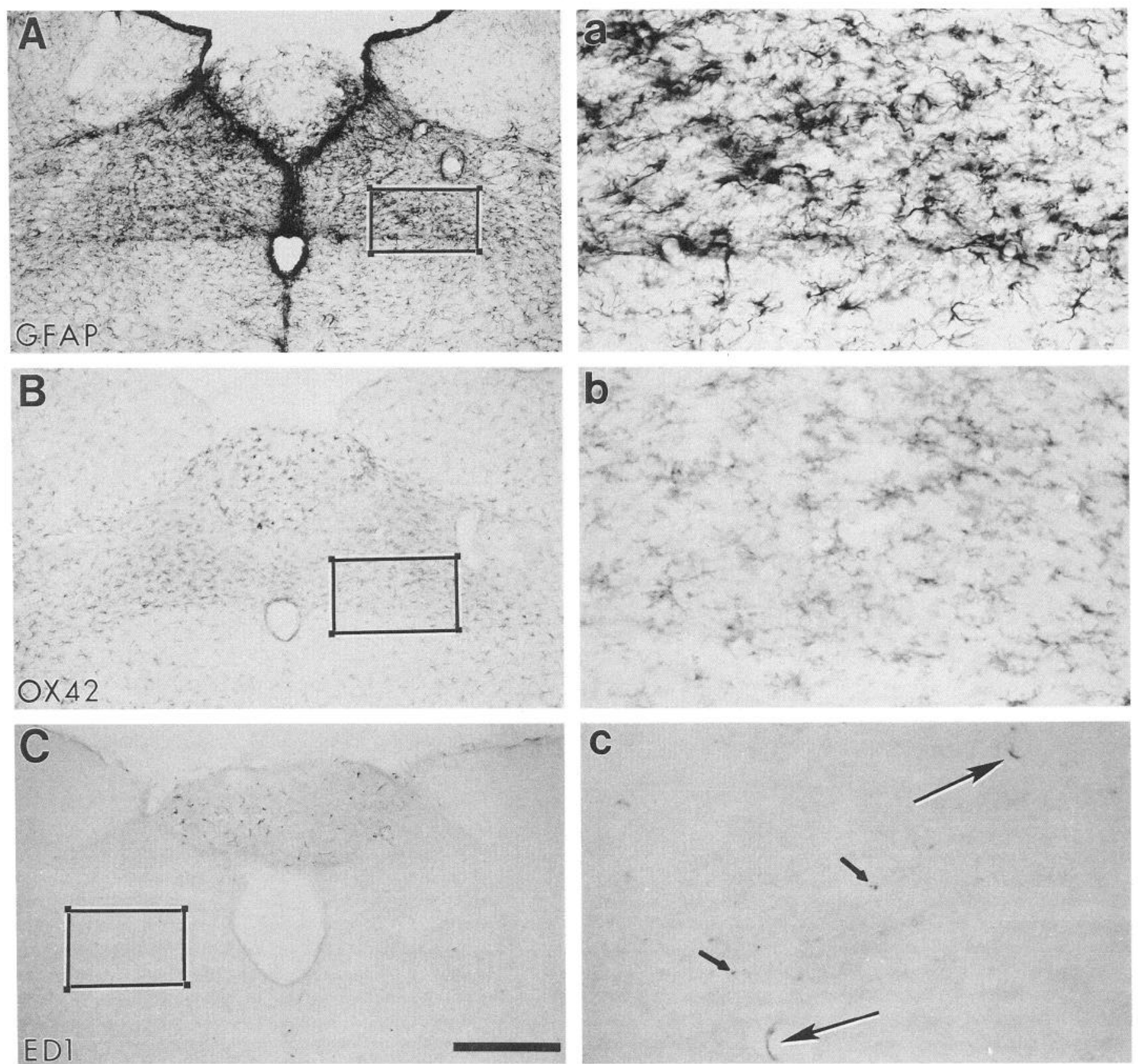

Figure 6. The normal distribution of GFAP-immunoreactive astrocytes $(A)$, OX42-immunoreactive microglia $(B)$, and ED1-immunoreactive brain macrophages $(C)$ in the dorsal medulla are illustrated. The boxed areas in $A-C$ are shown at higher magnification in $a-c$. GFAP-immunoreactive astrocytes and microglia are normally denser in the DMV and NST than in adjacent areas of the brainstem. ED1 immunoreactivity is confined to a sparse population of amoeboid microglia in the AP, flattened perivascular cells in the brainstem (long arrows in $c$ ), and other scattered small cells (short arrows in c). Scale bar, $500 \mu \mathrm{m}$ for $A-C . a-c$ are $4.5 \times$ the magnification of $A-C$.

$=14)$ injected animals. This decrease was first noticeable approximately $25 \mathrm{hr}$ after the onset of viral replication in the initially infected DMV, and was subsequently observed in other regions of the DMV and NST that contained severely infected neurons. In the same tissue sections, GFAP remained elevated above normal levels in areas containing infected neurons at earlier stages of viral replication. This is clearly illustrated by comparing the distribution of infected neurons and the intensity of GFAP staining in the left and right DMV and NST at intermediate to advanced stages of viral infectivity (Figs. $2 A, B ; 3 A, B$;
$4 A, B)$. As noted above, injection of either the ventral stomach or splenic pancreas led first to infection of many neurons in either the left or the right DMV (depending on the site of injection), with subsequent bilateral infection of the NST and scattered infected neurons in the contralateral DMV. Thus, neurons at various stages of viral replication were evident in the same tissue section. Comparison of the intensity of GFAP staining in these preparations revealed that regions containing only scattered infected neurons in an early stage of replication exhibited a pronounced increase in the intensity of GFAP staining 

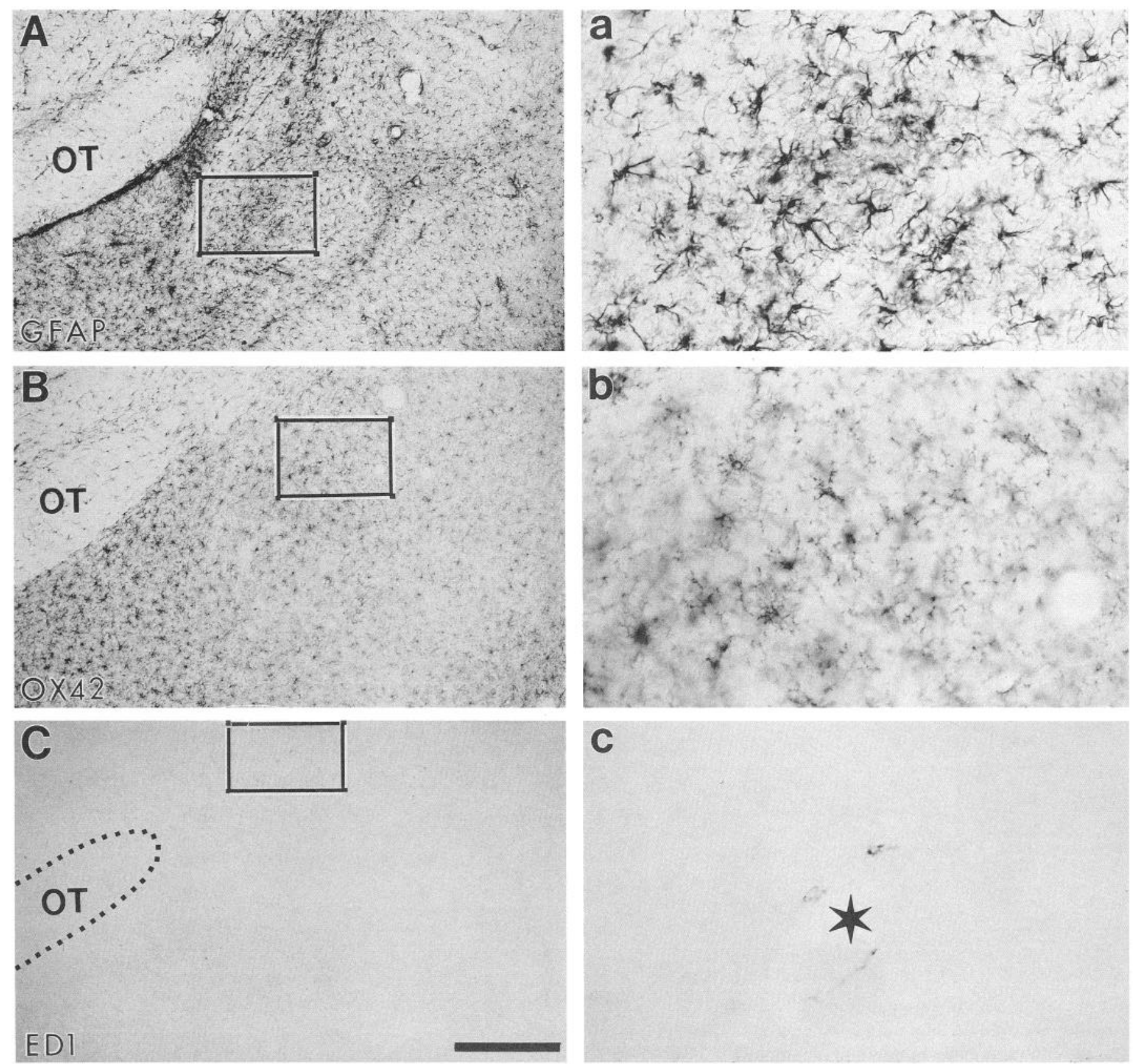

Figure 7. The normal distribution of astrocytes (GFAP), microglia (OX42), and brain macrophages (ED1) in the amygdala is shown in $A-C$, respectively. Staining densities for GFAP and ED1 are quite similar to those of the normal dorsal medulla (see Fig. 6), but OX42 staining is somewhat more intense. Asterisk in $c$ indicates a blood vessel surrounded by a few ED1-positive cells. Photographs on the right $(a-c)$ correspond to the indicated boxed areas in $A-C$. $O T$, optic tract. Scale bar, $500 \mu \mathrm{m}$ for $A-C . a-c$ are $4.5 \times$ the magnification of $A-C$.

compared to controls (e.g., compare GFAP immunoreactivity in the right DMV and in both NSTs in Fig. $2 B$ with the normal tissue shown in Fig. $6 A$ ). In contrast, areas containing large numbers of chronically infected neurons were distinguished by a substantial reduction in GFAP immunoreactivity to levels lower than seen in controls (e.g., compare the right DMV and NST in Fig. $3 B$ with the normal tissue in Fig. $6 A$ ). The same temporal changes in the intensity of GFAP immunoreactivity were apparent in the $\mathrm{CeA}$ at advanced postinoculation survival intervals in PRV-Bartha-infected animals. At $110 \mathrm{hr}$ postinoculation, GFAP immunoreactivity was substantially reduced in the heavily infected medial subdivision of this nucleus (Fig.
$5 A, B)$, but was increased relative to controls in the lightly infected subdivision (compare with the normal tissue in Fig. $7 A$ ).

Examination of cryostat sections processed for double-label immunofluorescence indicated that some of the GFAP-positive astrocytes in the dorsal vagal complex and along the medullary path of the vagal motor axons (see Fig. $1 A$ ) also contained viral antigens (Fig. 8). These double-labeled astrocytes apparently accounted for a very small percentage of the total viral labeling, although this was not quantified. Virus-positive astrocytes were not observed prior to $50 \mathrm{hr}$ postinjection with PRV-Becker, corresponding to approximately $20 \mathrm{hr}$ of viral replication in DMV motor neurons. After PRV-Bartha injection, a smaller 

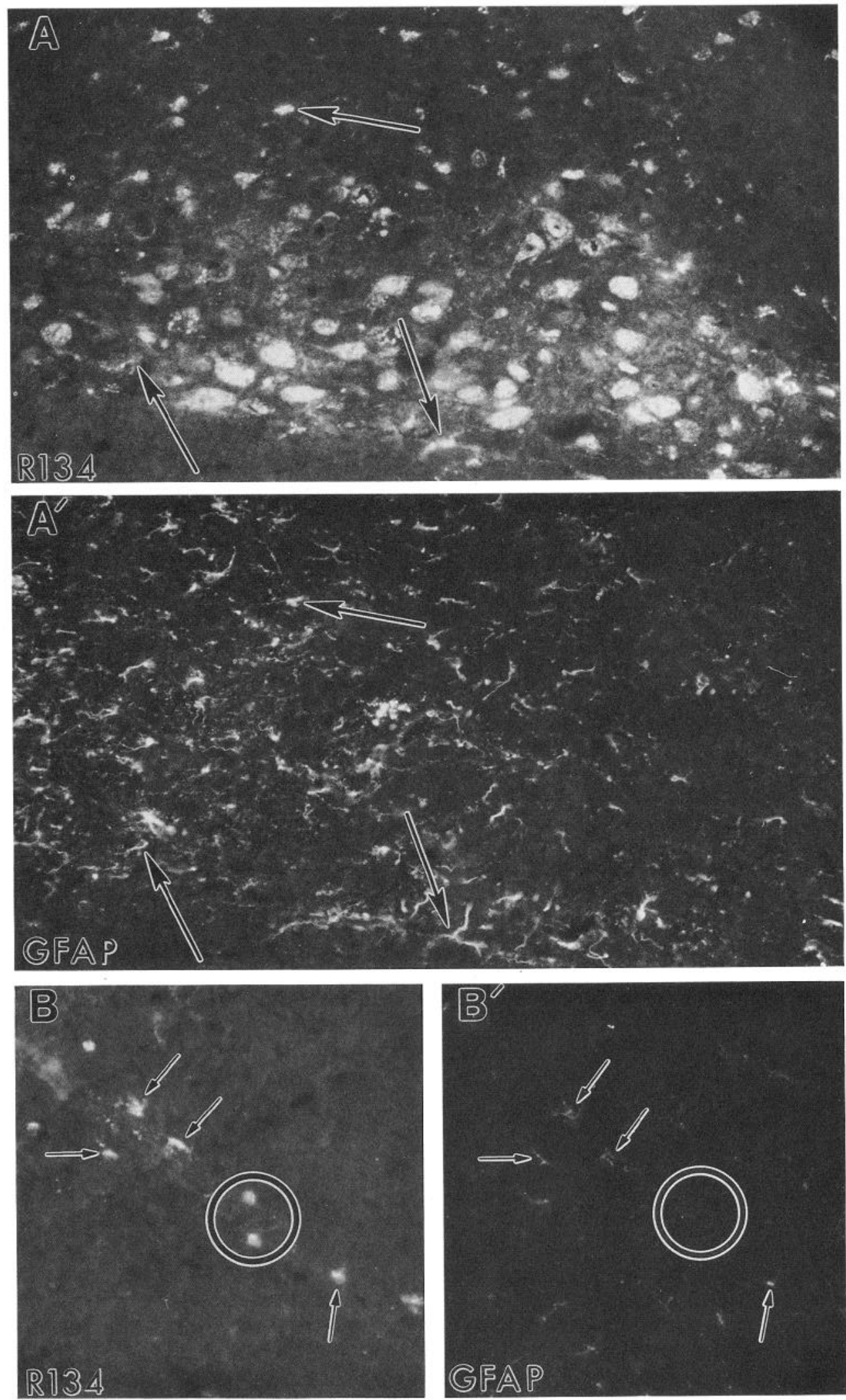

Figure 8. Double-labeling immunofluorescence in the same cryostat sections showing virus (R134) within GFAP-positive astrocytes in the DMV (arrows in $A, A^{\prime}$ ) and along the vagal motor neuron axon path (arrows in $B$, $\left.B^{\prime}\right) 70 \mathrm{hr}$ after injection of PRV-Becker into the ventral stomach wall. Not all of the infected cells seen along the axon path are GFAP positive ( ircled). These cells may be oligodendrocytes (see last section of Discussion). All panels are $150 \times$. number of GFAP-positive astrocytes containing viral antigens were observed after a similar period of DMV viral replication, and none were identified along the DMV axon path at even the longest postinjection survival times. The CeA was not examined for double-labeled astrocytes.
OX42 and ED1 labeling: microglia and brain macrophages

Normal distribution. Our observations on the distribution of OX42- and ED1-immunoreactive cells in the normal adult rat are consistent with a recent report (Milligan et al., 1991a). In 
the dorsal medulla, the OX42 monoclonal antibody lightly labeled resting ramified microglia distributed throughout the gray and white matter, and also labeled amoeboid microglia (resident brain macrophages) in the AP (Fig. $6 B$ ). Microglia were evenly distributed and relatively uniform in size, with small cell bodies and branching, crenelated processes (Fig. 6b), as originally described by Del Rio-Hortega (1932). The staining intensity of individual cells was somewhat higher in the DMV and NST relative to adjacent nuclei, in a manner similar to the denser GFAP immunoreactivity in these nuclei.

In normal material, ramified microglia were not labeled with the ED1 antibody. In contrast, the OX42-positive amoeboid microglia in the AP were always EDl positive (Fig. $6 \mathrm{C}$ ), as confirmed by double-label immunofluorescence (not shown). The dual OX42/ED1 staining of these cells is consistent with dual OX42/ED1 staining of amoeboid microglia in other circumventricular organs in the normal adult rat brain (C. E. Milligan, personal communication). Amoeboid microglia were intensely stained with both antibodies and were typically more elongated than ramified microglia.

Two additional morphological classes of cells positive for both OX42 and ED1 were observed in normal material. These were scattered flat perivascular cells (Fig. $6 c$ ), and occasional round cells that were confined to the meninges and ventricular lining. In the amygdala of normal rats, OX 42 identified resting ramified microglia that were stained more intensely than microglia in the medulla (Fig. $7 B$ ), and both ED1 and OX42 identified a few perivascular cells (Fig. $7 \mathrm{C}$ ).

Microglial and brain macrophage response to neuronal virus infection. Simultaneous with the first immunocytochemical evidence of viral rcplication in DMV motor neurons, a generalized hypertrophy of OX42-immunoreactive ramified microglia was evident in the dorsal vagal complex in a manner analogous to the hypertrophy of astrocytes noted above (compare Fig. $2 C$ with the normal material in Fig. $6 B$ ). In accordance with previous work examining the response of $\mathrm{OX} 42$-positive microglia to axotomy-induced neural degeneration (Milligan et al., 1991b; Rinaman et al., 1991), some of the OX42-positive ramified microglia responding to late stages of central PRV infection also expressed ED1 immunoreactivity (not shown). As neuronal infection progressed, the staining intensity and size of OX42positive microglia continued to increase, implying both an upregulation of $\mathrm{C} 3 \mathrm{bi}$ complement receptor on individual cells as well as cellular hypertrophy (Figs. $2 c, 3 c, 4 c$ ). Heightened staining intensity of OX42-positive microglia was also increasingly evident in medullary areas adjacent to the vagal complex that lacked viral immunoreactivity (Figs. $2 C, 3 C, 4 C$ ). Nevertheless, the most striking concentration of $\mathrm{OX} 42$ immunoreactivity corresponded to focal areas of pronounced viral infection that were also characterized by the reduced GFAP immunoreactivity described above (Figs. $2 A-C ; 3 A-C ; 4 A-C$ ). Analysis of cryostat sections processed for double-fluorescent localization of virus and $\mathrm{OX} 42$, however, failed to reveal viral antigens within OX42positive cells that were morphologically identifiable as ramified microglia (Fig. 9B, $B^{\prime}$ ).

Initial changes in ED1-immunoreactive brain macrophages lagged approximately $24 \mathrm{hr}$ behind the first changes in astrocytes and microglia described above. Approximately $50 \mathrm{hr}$ after PRVBecker injection, and $70 \mathrm{hr}$ after PRV-Bartha injection, an increased number and staining intensity of perivascular ED1-positive cells was noted, and amoeboid microglia in the AP also demonstrated increased ED1 immunoreactivity (Fig. 2D). At the latest stages of viral replication in the DMV, corresponding to the longest survival times after virus injection, a new morphological class of cells positive for both OX42 and ED1 was recognized that was not observed in normal rats (see Figs. $3 c, d$; $4 c, d)$. These brain macrophages were large and generally round, had few or no labeled cytoplasmic processes, and were prominent in the most infected areas. The majority were located in the immediate vicinity of large blood vessels (Fig. $3 c$ ), but many were also apparent within the neuropil (Fig. 4c). When these brain macrophages appeared, ED1-positive cells with the morphology of amoeboid microglia were reduced or were no longer identifiable in the AP (Figs. $3 D, 4 D$ ). However, many round macrophages were present in the AP at these stages (Fig. 4D) and there was also an increased number of round macrophages in the meninges. At the longest postinjection survival times, round brain macrophages were also apparent within adjacent uninfected areas, but their density decreased with increasing distance from the infected nuclei. For example, many macrophages were located around blood vessels within the hypoglossal nuclei and gracile/cuneate areas, despite the lack of viral antigen there (Fig. 4D). Dual labeling immunofluorescence revealed that a subset of the round OX42/ED1-positive brain macrophages in the DMV and NST also contained viral antigen (Fig. 9A, $A^{\prime}$ ). These virus-immunoreactive macrophages were observed only at times corresponding to late stages of viral replication, and were (qualitatively) more prevalent following PRV-Becker infection than following PRV-Bartha infection.

At the longest survival time examined after PRV-Bartha injection (110 hr), viral infection in amygdala neurons was accompanied by a pronounced hypertrophy of OX42-immunoreactive microglia that was evident both within and surrounding the area of neuronal infection (compare Fig. $5 C$ with the normal tissue in Fig. $7 B$ ). A slight increase in the number of ED1positive perivascular cells was observed relative to control animals (compare Fig. $5 D$ to Fig. $7 C$ ), similar to that seen in the dorsal medulla at intermediate stages of viral replication. However, this period of viral replication in CeA neurons was apparently insufficient to recruit significant numbers of ED1-positive brain macrophages.

\section{Discussion}

These data demonstrate a directed, temporally organized response of astrocytes, microglia, and brain macrophages to infection of neurons with virulent or attenuated strains of PRV. The progressive involvement and phenotypic alterations of these cells at sites of neuronal infectivity strictly correlate with the stage of viral replication and pathology of the infected neurons. Furthermore, the immunocytochemical double-labeling analysis suggests that astrocytes and macrophages permit viral invasion and possible replication, whereas ramified microglia do not. Nevertheless, spread of virus to other areas of the neuraxis always occurs in a manner consistent with transport exclusively through multisynaptic neuronal circuits rather than through indiscriminate spread. Considered together with previous rcports of the temporally predictable transport of PRV through functionally related populations of neurons (Martin and Dolivo, 1983; Rouiller et al., 1986, 1989; Strack et al., 1989a,b; Card et al., 1990, 1991, 1992; Strack and Loewy, 1990; Miselis et al., 1991; Sternini et al., 1991), our observations suggest that the non-neuronal cellular response to PRV infection effectively isolates the virus and restricts it from traveling extracellularly. Thus, rather than reflecting nonspecific spread, the involvement 

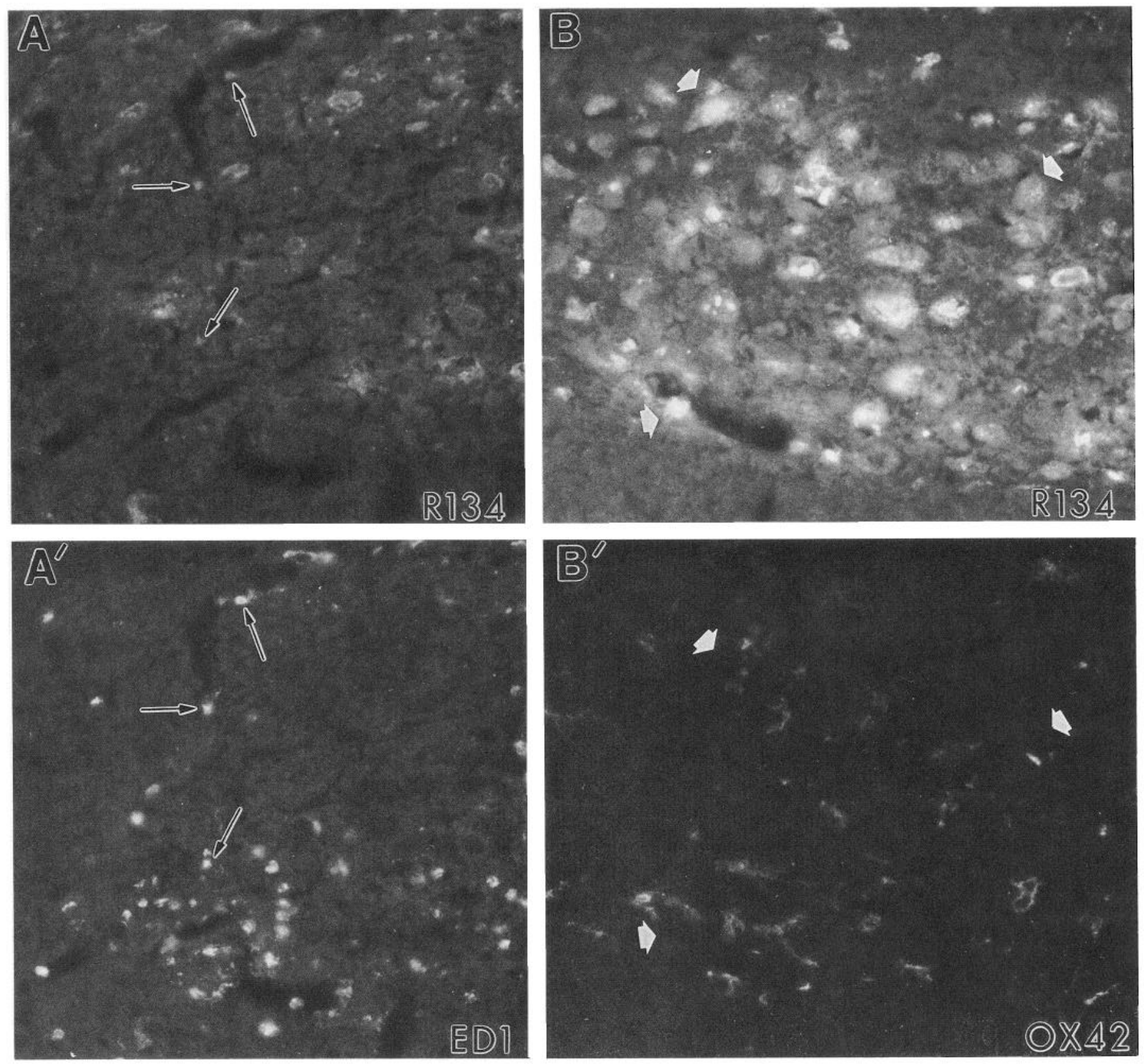

Figure 9. $A$ and $A^{\prime}$, Double-labeling immunofluorescence in the same cryostat section showing virus (R134) within ED1 brain macrophages in the DMV (arrows), 70 hours after injection of PRV-Becker into the ventral stomach wall. $B$ and $B^{\prime}$, ninety-six hr after injection of PRV-Bartha into the ventral stomach wall, double-labeling immunofluorescence in the same cryostat section shows the close approximation of OX42-positive microglia with virus-infected (R134) neurons, but no examples of double-labeled microglia are seen. Arrows provide points of reference. All panels are $220 \times$.

of glia and macrophages may facilitate the specific transneuronal passage of PRV.

\section{Neuropathology following viral infection}

The cytopathic effect of PRV replication in neurons is an important consideration in evaluating the non-neuronal response to infection and the subsequent spread of virus to other areas of the CNS. PRV may kill neurons by a direct cytotoxic effect, by inducing a complement receptor-mediated immune attack directed at infected neurons, or by a combination of both. Whereas the genotype of the virus clearly influences the extent and degree of both neuronal and non-neuronal infection and virulence (Kimman et al., 1992; Zsak et al., 1992), little is known regarding the existence of PRV genes specifically involved in neuronal killing. For example, it is not known if PRV encodes the novel $\gamma_{1} 34.5$ neurovirulence gene recently identified in HSV-1 by Chou et al. (1990). However, several nonessential PRV membrane glycoproteins have been implicated in virulence (Ben-Porat and Kaplan, 1985; Wittmann and Rzhia, 1989; Kimman et al., 1992; Zsak et al., 1992). We previously demonstrated that genes mapping to the unique short region of the PRV genome (specifically gI and gp63) influence target cell recognition and virulence in rats (Card et al., 1991, 1992), and this finding has been confirmed in pigs (Kimman et al., 1992). In 
addition, a PRV-Becker strain defective only in glycoprotein genes encoding gI and gIII produces reduced virulence in rats similar to that produced by PRV-Bartha, which is also defective in these genes (Card et al., 1992). This may be significant in the delayed pathology displayed by neurons infected with PRVBartha, as the gIII glycoprotein is a major target for cytotoxic T lymphocytes (Zuckermann et al., 1990). Cytotoxic T cells enter the CNS under both normal and pathological circumstances (Booss et al., 1983; Wekerle et al., 1986; Salamat et al., 1988; Hickey et al., 1989), and a number of other studies have also demonstrated that some recognize herpesvirus glycoproteins (Glorioso et al., 1985; Zarling et al., 1986, 1988; Martin et al., 1987, 1988, 1989, 1990; Johnson et al., 1990; Tigges et al., 1992). Collectively, these data suggest that certain PRV gene products may elicit the neuronal, as well as the non-neuronal, response to viral infection.

\section{Astrocytic response to neuronal infection}

A number of studies have demonstrated that alpha herpesvirus infection of neurons ultimately leads to infection of glia in the immediate vicinity of the most chronically afflicted cells. Infection of glia is not surprising because astrocytic membranes exhibit a high affinity for HSV (Vahlne et al., 1978, 1980) and astrocytes are generally permissive for alpha herpesvirus rcplication (Dow and McFerran, 1962; Kristensson et al., 1974, 1982; Bak et al., 1977). However, viral replication in astrocytes does not necessarily reflect production of infectious virions. In an early study of the neuropathogenesis induced by inoculation of PRV into the footpad of mice, Field and Hill (1974) reported that infection of neurons in the dorsal root ganglia is accompanied by infection of adjacent satellite glial cells. However, their electron microscopic analysis demonstrated that the glial infection is abortive due to a defect in assembly that prevents envelopment of newly replicated capsids. On this basis, they concluded that spread of virus occurs only through neurons, as the glia are apparently incapable of producing the mature enveloped form of virus that is necessary for viral egress. A subsequent analysis by Bak et al. (1977) indicated that a similar defect in viral replication may also be present in CNS astrocytes, and we have noted an absence of mature enveloped virions in the cytoplasm of PRV-infected astrocytes (J. P. Card, unpublished observations). Our present light microscopic findings also argue against spread of virus from infected astrocytes. In particular, we observed very focal astroglial responses that always followed neuronal infection and were strictly associated with the most chronically infected neurons. In no instance did we observe the widespread necrotizing patterns of infection that one would expect if astrocytes released mature infectious virus into the extracellular space or if virus spread by nonspecific cellcell fusion (syncytia formation). Collectively, these data argue against a role for astroglia in dissemination of these strains of $\mathrm{PRV}$ in the CNS.

By examining astrocytic GFAP immunoreactivity in areas of PRV neuronal infection, a strict correlation between the extent of neuronal viral replication and GFAP expression was apparent. A general increase in GFAP occurred in the vagal nuclei and in the CeA well before infected neurons appeared morphologically compromised. In particular, GFAP increased bilaterally in the DMV and NST concomitant with the first signs of viral infection in scattered DMV neurons on only one side. The bilateral GFAP response in the DMV/NST may reflect an as- trocytic sensitivity to disruption of normal metabolism and activity within these highly interconnected nuclei. Alternatively, astrocytes may respond to very early infection of neurons that is below the level of immunocytochemical detection. Another possibility is that the bilateral astrocytic reaction reflects the widespread distribution of DMV motor neuron dendrites that extend throughout the ipsilateral and contralateral DMV and NST (Shapiro and Miselis, 1985). These hypotheses require further examination.

As viral replication progressed, a pronounced reduction of GFAP occurred in focal areas containing severely infected neurons while less infected areas continued to display heightened GFAP. The eventual reduction of GFAP in areas of chronic PRV infection contrasts with the persistent increase in GFAP that accompanies axotomy-induced neural degeneration in the DMV and other motor nuclei (Graeber and Kreutzberg, 1986; Murray et al., 1990; Rinaman et al., 1991). However, progressive disappearance of GFAP staining has been noted following certain excitotoxic lesions, and is correlated with cytoskeletal changes in affected astrocytes that reduce immunoreactive glial filaments (Dusart et al., 1991). It is probable that the decreased GFAP immunoreactivity observed in the present work results from astrocytic viral infection, even if this infection leads only to abortive viral replication. Astrocytes express class I major histocompatibility complex (MHC) in response to exposure to $\gamma$-interferon or murine hepatitis virus (Hirsch et al., 1983; Wong et al., 1984; Massa et al., 1986), and MHC antigen expression renders infected cells susceptible to lysis by cytotoxic $\mathrm{T}$ lymphocytes (Booss et al., 1983; Wekerle et al., 1986; Salamat et al., 1988; Hickey et al., 1989; Plata-Salaman, 1990). Therefore, it is possible that astrocytes infected with PRV express MHC antigens and become cytotoxic targets. In contrast with this theory, Weinstein et al. (1990) reported that astrocytes infected with HSV-1 did not express MHC antigens. Consequently, the reduction in GFAP immunoreactivity observed in our analysis may reflect differences in the abilities of HSV-1 and PRV to induce $\mathrm{MHC}$ expression by astrocytes. Alternatively, the observed reduction of GFAP may be a direct pathological consequence of PRV infection of astrocytes. Neither of these possibilities can be cxcluded at the present time.

\section{Microglial and brain macrophage response to neuronal infection}

It is clear that alpha herpesvirus infection of the CNS produces a complex cascade of cellular responses that is not limited to neurons and astrocytes. In our analysis, OX42-immunoreactive microglia and ED1-immunoreactive brain macrophages also exhibited profound responses to PRV neuronal infection that were unique to each cell type. Hypertrophy and heightened OX42 immunoreactivity in ramified microglia was evident shortly after the onset of viral replication in neurons, and continued to increase throughout the course of viral infection. A dramatic increase in the staining intensity of OX42-immunoreactive microglia also occurs following axotomy-induced neuronal degeneration in adult rats (Milligan et al., $199 \mathrm{lb}$; Rinaman et al., 1991) or excitotoxic lesions of the CNS (Marty ct al., 1991). The increased density of OX42 staining in individual microglia implies upregulation of the $\mathrm{C} 3 \mathrm{bi}$ complement receptor, suggesting a role for these cells in an immune response to the infection. Although quantitative measures were not applied in the present work, our observations suggest an increased density 
of microglia in infected areas, perhaps reflecting local proliferation and/or mobilization from adjacent areas, perhaps in response to chemotactic signals (see Milligan et al., 1991b). Giulian et al. (1991) recently identified a microglial mitogen that is secreted by astrocytes during development and after traumatic injury of the brain. It will be important to determine whether this factor or others are induced by central viral infection. Interestingly, the hypertrophy and potential proliferation of $\mathrm{mi}$ croglia may also serve to enhance astrogliosis at the site of infection. For example, the cytokine interleukin-1 is secreted by microglia (Giulian et al., 1986) and stimulates astrogliosis at sites of neuronal injury (Giulian et al., 1988).

The third type of non-neuronal cell examined in the present work was ED1-positive brain macrophages. Phagocytes are known to respond to both infection and neural degeneration in the CNS (Graeber et al., 1988, 1990; Ling and Leong, 1988; Streit et al., 1988; Coffey et al., 1990; Weinstein et al., 1990; Marty et al., 1991; Milligan et al., 1991 b; Rinaman et al., 1991). Similarly, brain macrophages are increasingly recognized as important to host defense against CNS viral infection, but the mechanisms by which they are enlisted are incompletely understood (Morahan et al., 1985; Lipkin et al., 1988). In the present work, the temporal appearance and distribution of ED1 immunoreactive brain macrophages were tightly correlated with the late stages of viral infection. This was clearly evident in examining the temporal appearance of brain macrophages in the DMV and CeA following injection of PRV-Bartha. Infected neurons and an accompanying increase in GFAP and OX42 immunoreactivity were apparent in the DMV within 50-60 hr postinjection, but substantial numbers of brain macrophages did not appear until about $2 \mathrm{~d}$ later, at $100-110 \mathrm{hr}$ postinjection. Similarly, the CeA contained PRV-infected neurons by $85 \mathrm{hr}$ after inoculation, and substantial numbers of infected cells were present at $110 \mathrm{hr}$. However, while this $25 \mathrm{hr}$ period of viral replication in amygdala neurons was sufficient to elicit a prominent response in astrocytes and microglia, it was insufficient to mobilize more than a few ED1-immunoreactive macrophages to the site of infection. These results clearly demonstrate that infiltration of these cells at the site of viral infection depends on the severity of neuronal infection, and suggest that this infiltration occurs in response to specific signals arising from degenerating neurons or glia.

Our data do not specifically address the source of infiltrating EDl-immunoreactive brain macrophages. In addition to a possible contribution by resident CNS brain macrophages (amoeboid microglia in the circumventricular organs, perivascular cells, and cells in the meninges and ventricular lining), pcripheral monocytes probably provide a separate direct source of brain macrophages. A peripheral source would be consistent with literature suggesting that phagocytic monocytes invade the adult CNS from the vasculature under certain pathological conditions (Ling and Leong, 1988; Weinstein et al., 1990; for review, see Milligan et al., 1991b). In the present work, round ED1-immunoreactive macrophages were preferentially associated with blood vessels located either within or close to the afflicted region; these cells were never observed in normal animals or in animals at earlier stages of infection. Examination of the distribution of these cells at the longest survival intervals after PRV injection demonstrated a clear density gradient, with most brain macrophages located around blood vessels in areas adjacent to chronically infected neurons. While these observations suggest that a subpopulation of the ED1-immunoreactive cells observed in the present study are blood-borne phagocytes, they do not exclude the possibility that some may be derived from the resident brain macrophage population.

\section{Status of blood-brain barrier following central PRV infection}

The possibility that peripheral monocytes gain access to the CNS through the vasculature raises important questions regarding the integrity of the blood-brain barrier (BBB) during the course of viral infection, and the role that blood-borne cellular elements play in the response to central viral infection. As noted above, substantial numbers of macrophages appeared to gain access to the brainstem via the area postrema, which contains fenestrated capillaries and therefore lacks a BBB. Nevertheless, large numbers of ED1-immunoreactive cells were also associated with blood vessels in the DMV and overlying NST, areas in which the BBB is normally intact. Weinstein et al. (1990) reported that granulocytes, monocytes, and $\mathrm{T}$ lymphocytes accumulate in areas of the CNS in which neurons have been infected by peripheral inoculation of HSV-1. It is thus clear that blood-borne cellular elements have access to the infected CNS, but it is not known whether this access is limited to areas in which the BBB is normally or pathologically absent.

Stroop et al. (1990) have recently reported focal breakdowns of the BBB in response to HSV-1 infection of the olfactory and entorhinal cortices. In preliminary studies we have also noted that advanced PRV infection of the DMV leads to some loss of $\mathrm{BBB}$ integrity, which may be correlated with the ability of peripheral monocytes to enter (L. Rinaman, J. P. Card, and L. W. Enquist, unpublished observations). Massive infiltration of brain macrophages also follows axotomy-induced degeneration in the thalamus and in the DMV in neonatal rats, prior to formation of the BBB, whereas the same lesions performed in adult rats elicit far less macrophage infiltration (Milligan et al., 1991b; Rinaman et al., 1991). The macrophage response observed late in PRV infection is thus quite similar to what occurs following neuronal degeneration in neonatal rats, suggesting that an incomplete BBB may facilitate peripheral macrophage infiltration given the appropriate signals for their recruitment. Additionally or alternatively, some requisite concentration of chemotactic factor(s) may be required for macrophage infiltration that is achieved only under certain circumstances. For example, the synchronous cell death that occurs following neonatal (but not adult) axotomy may provide the appropriate signal for macrophage recruitment (for discussion, see Milligan et al., 1991a,b). This theory may apply to the present work, for viral infection ultimately produces relatively synchronized neuronal death within neurons occupying discrete nuclei.

\section{Differential uptake and replication of $P R V$ by non-neuronal cells}

We observed an apparent variability in PRV uptake and replication by different types of non-neuronal cells, consistent with recent work using $\mathrm{HSV}-1$. Several laboratories have reported HSV-1 infection of astrocytes similar to our observations with PRV (Bak et al., 1977; Kristensson et al., 1978, 1982). Recent studies have also reported that oligodendrocytes and macrophages exhibit variable resistance to infection by HSV-1 (Daniels et al., 1978; Morahan, 1983; Morahan et al., 1985; Sarmiento, 1988; Sarmiento and Kleinerman, 1990; Thomas et al., 1991). We did not examine the infectivity of oligodendrocytes, 
but they may comprise the population of PRV-immunoreactive cells that we observed adjacent to DMV efferent axons that course through the brainstem tegmentum. Many of these cells did not exhibit GFAP immunoreactivity, and their morphology was similar to that of oligodendrocytes. Alternatively, these cells could be astrocytes in which GFAP immunoreactivity had disappeared with prolonged replication of the virus.

Subpopulations of astrocytes and macrophages were infected by PRV, and the extent of infection of these cell types was lower in animals infected with the attenuated strain of virus. This may simply reflect the delayed neuronal pathology produced by PRVBartha infection, the deletions and mutations present in the PRV-Bartha genome, or differences in host cellular factors essential for viral replication. For example, attenuated strains of PRV do not replicate as efficiently in alveolar macrophages as virulent strains (Inglesias et al., 1989).

In contrast to astrocytes and brain macrophages, ramified microglia contained no detectable viral antigen at any postinjection survival time. A lack of viral antigen in ramified microglia was also reported following central HSV-1 infection, despite a pronounced microglial response to infection (Weinstein et al., 1990). Based on these results, we suggest that, though ramified microglia respond to viral infection, they are themselves nonpermissive. Whilc we cannot exclude the unique possibility that viral infection may occur in ramified microglia and subsequently alter their OX42 phenotype, previous work has shown that actively phagocytic ramified microglia maintain their characteristic appearance and OX42 staining following axotomy-induced neural degeneration (Rinaman et al., 1991).

\section{Summary}

These findings demonstrate that infection of neurons in the CNS with virulent and attenuated strains of pseudorabies virus produces significant alterations in the phenotype and distribution of astrocytes, microglia, and brain macrophages in the region of infection. The progressive, virally induced changes in glial morphology and the recruitment of brain macrophages were strictly correlated with the pathological state of the infected neurons, which in turn depended on the virulence of the infecting strain. Furthermore, we noted that some astrocytes and macrophages were susceptible to PRV uptake and possible replication, but that ramified microglia showed no signs of viral infection. The non-neuronal response appeared to restrict nonspecific spread of virus by isolating the most severely afflicted cells. Spread of virus to other areas of the neuraxis always occurred in a manner that was consistent with viral transport through multisynaptic neuronal circuits rather than indiscriminate spread of virus through the extracellular space or via glial elements. Collectively, these observations suggest that the spatiotemporal responses of glia and macrophages at sites of neuronal infection act to contain the viral infection, and this spatial containment is defeated only by the transneuronal passage of virus through synaptically linked populations of neurons.

\section{References}

Adams JC (1981) Heavy metal intensification of DAB-based HRP reaction product. J Histochem Cytochem 29:255.

Bak IJ, Markham CH, Cook ML, Stevens JG (1977) Intraaxonal transport of herpes simplex virus in the rat central nervous system. Brain Res 136:415-429.

Bartha A (1961) Experimental reduction of virulence of Aujeszky's disease virus. Magy Allatorv Lapja 16:42-45.
Becker CH (1967) Zur primaren Schadingung vegetativer Ganglien nach infektion mit dem Herpes suis Virus bei verschiedenen Tierarten. Experentia 23:209-217.

Ben-Porat T, Kaplan AS (1985) Molecular biology of pseudorabies virus. In: The herpesviruses (Roizman B, ed), pp 105-1773. New York: Plenum.

Blessing WW, Li YW, Wesselingh SL (1991) Transneuronal transport of herpes simplex virus from the cervical vagus to brain neurons with axonal inputs to central vagal sensory nuclei in the rat. Neuroscience 42:261-274.

Booss J, Esiri MM, Tiurtellotte WW, Mason DY (1983) Immunohistological analysis of $T$ lymphocyte subsets in the central nervous system in chronic progressive multiple sclerosis. J Neurol Sci 62:219-232.

Card JP, Rinaman L, Schwaber JS, Miselis RR, Whealy ME, Robbins AK, Enquist LW (1990) Neurotropic properties of pseudorabies virus: uptake and transneuronal passage in the rat central nervous system. J Neurosci 10:1974-1994.

Card JP, Whealy ME, Robbins AK, Moore RY, Enquist LW (1991) Two $\alpha$-herpesvirus strains are transported differentially in the rodent visual system. Neuron 6:957-969.

Card JP, Whealy ME, Robbins AK, Enquist LW (1992) Pseudorabies virus envelope glycoprotein gI influences both neurotropism and virulence during infection of the rat visual system. J Virol 66:30323041 .

Chou J, Kern ER, Whitley RJ, Roizman B (1990) Mapping of herpes simplex virus-1 neurovirulence to $\gamma_{1} 34.5$, a gene nonessential for growth in culture. Science 250:1262-1266.

Coffey PJ, Perry VH, Rawlins JNP (1990) An investigation into the early stages of the inflammatory response following ibotenic acidinduced neuronal degeneration. Neuroscience 35:121-132.

Cook ML, Stevens JG (1973) Pathogenesis of herpetic neuritis and ganglionitis in mice-evidence for intra-axonal transport of infection. Infec Immun 7:272-288.

Daniels CA, Kleinerman ES, Snyderman R (1978) Abortive and productive infections of human mononuclear phagocytes by type 1 herpes simplex virus. Am J Pathol 91:119-129.

Del Rio-Hortega P (1932) Microglia. In: Cytology and cellular pathology of the nervous system, vol 2 (Penfield W, ed), pp 482-534. New York: Hoeber.

Dusart I, Marty S, Peschanski M (1991) Glial changes following an excitotoxic lesion in the CNS. II. Astrocytes. Neuroscience 45:541549.

Field HJ, Hill TJ (1974) The pathogenesis of pseudorabies in mice following peripheral inoculation. J Gen Virol 23:145-157.

Giulian D, Baker TJ, Shih L-C, Lachman LB (1986) Interleukin-1 of the central nervous system is produced by ameboid microglia. J Exp Med 164:594-604.

Giulian D, Woodward J, Young DG, Krebs JF, Lachman LB (1988) Interleukin- 1 injected into mammalian brain stimulates astrogliosis and neovascularization. J Neurosci 8:2485-2490.

Giulian D, Johnson B, Krebs JF, George JK, Tapscott M (1991) Microglial mitogens are produced in developing and injured mammalian brain. J Cell Biol 112:323-333.

Glorioso J, Kees U, Kummel G, Kirchner H, Krammer PH (1985) Identification of herpes simplex virus type 1 (HSV-1) glycoprotein $\mathrm{gC}$ as the immunodominant antigen for HSV-1 specific memory cytotoxic T lymphocytes. J Immunol 135:575.

Graeber MB, Kreutzberg GW (1986) Astrocytes increase in glial fibrillary acidic protein during retrograde changes of facial motor neurons. J Neurocytol 15:363-373.

Graeber MB, Streit WJ, Kreutzberg GW (1988) Axotomy of the rat facial nerve leads to increased CR3 complement receptor expression by activated microglial cells. J Neurosci Res 21:18-24.

Graeber MB, Streit WJ, Kiefer R, Schoen SW, Kreutzberg GW (1990) New expression of myelomonocytic antigens by microglia and perivascular cells following lethal motor neuron injury. J Neuroimmunol 27:121-132.

Gray TS (1983) The morphology of somatostatin-immunoreactive neurons in the lateral nucleus of the rat amygdala. Peptides 4:663668.

Hickey WF, Hsu BL, Kimura H (1989) T cell entry into the rat central nervous system. FASEB J [Suppl 1] 3:A482.

Higgins GA, Schwaber JS (1983) Somatostatinergic projections from the central nucleus of the amygdala to the vagal nuclei. Peptides 4:657-662. 
Hirsch M-R, Wietzergin J, Pierres M, Goridis C (1983) Expression of Ia antigens by cultured astrocytes treated with gamma-interferon. Neurosci Lett 41:199-204.

Inglesias G, Pijoan C, Molitor T (1989) Interactions of pseudorabies virus with swine alveolar macrophages I: virus replication. Arch Virol 104:107-115.

Johnson RM, Lancki DW, Fitch FW, Spear PG (1990) Herpes simplex virus glycoprotein $\mathrm{D}$ is recognized as antigen by $\mathrm{CD} 4+$ and $\mathrm{CD} 8+$ $T$ lymphocytes from infected mice: characterization of $\mathrm{T}$ cell clones. J Immunol 145:702-710.

Kimman TG, de Wind N, Oei-Lie N, Pol JMA, Berns AJM, Gielkens ALJ (1992) Contribution of single genes within the unique short region of Aujeszky's disease virus (suis herpesvirus type 1) to virulence, pathogenesis and immunogenicity. J Gen Virol 73:243-251.

Kristensson K, Lycke E, Sjostrand .J (1971) Spread of herpes simplex virus in peripheral nerves. Acta Neuropathol (Berl) 17:44-53.

Kristensson K, Ghetti B, Wisniewski HM (1974) Study on the propagation of herpes simplex virus (type 2) into the brain after intraocular injection. Brain Res 69:189-201.

Kristensson K, Vahlne A, Persson A, Lycke E (1978) Neural spread of herpes simplex virus types 1 and 2 in mice after corneal or subcutaneous (footpad) inoculation. J Neurol Sci 35:331-340.

Kristensson K, Nennesmo I, Persson L, Lycke E (1982) Neuron to neuron transmission of herpes simplex virus - transport of virus from skin to brainstem nuclei. J Neurol Sci 54:149-156.

Kuypers HGJM, Ugolini G (1990) Viruses as transneuronal tracers. Trends Neurosci 13:71-75.

Lazarides E (1982) Intermediate filaments: a chemically heterogeneous, developmentally regulated class of proteins. Annu Rev Biochem 51:219-250.

Ling EA, Leong SK (1988) Infiltration of carbon-labelled monocytes into the dorsal motor nucleus following an intraneural injection of ricinus communis agglutinin-60 into the vagus nerve in rats. J Anat 159:207-218.

Lipkin WI, Tyler KL, Waksman BH (1988) Viruses, the immune system and central nervous system diseases. Trends Neurosci 11:4345.

Margolis 'T, Togni B, LaVail J, Dawson CR (1987) Identifying HSV infected neurons after ocular inoculation. Curr Eye Res 6:119-126.

Margolis TP, LaVail JH, Setzer PY, Dawson CR (1989) Selective spread of herpes simplex virus in the central nervous system after ocular inoculation. J Virol 63:4756-4761.

Martin S, Moss B, Berman PW, Laskey LA, Rouse BT (1987) Mechanisms of antiviral immunity induced by a vaccinia virus recombinants expressing herpes simplex virus type 1 glycoprotein D: cytotoxic T cells. J Virol 61:726-734.

Martin S, Courtney RJ, Fowler G, Rouse BT (1988) Herpes simplex virus type 1 -specific cytotoxic $T$ lymphocytes recognize virus nonstructural proteins. J Virol 62:2265-2273.

Martin S, Cantin E, Rouse BT (1989) Evaluation of antiviral immunity using vaccinia virus recombinants expressing cloned genes for herpes simplex virus type 1 glycoproteins. J Gen Virol 70:1359-1370.

Martin S, Zhu X, Silverstein SJ, Courtney RJ, Yao F, Jenkins FJ, Rouse BT (1990) Murine cytotoxic T lymphocytes specific for herpes simplex virus type 1 recognize immediate early protein ICP4 but not ICP0. J Gen Virol 71:2391-2399.

Martin X. Dolivo M (1983) Neuronal and transneuronal tracing in the trigeminal system of the rat using herpes virus suis. Brain Res 273:253-276.

Marty S, Dusart I, Peschanski M (1991) Glial changes following an excitotoxic lesion in the CNS-I. Microglia/macrophages. Neuroscience 45:529-539.

Massa P, Dorries R, terMeulen U (1986) Viral particles induce Ia antigen expression in astrocytes. Nature 320:543-546.

McLean IW, Nakane PK (1974) Periodate-lysine-paraformaldehyde fixative. A new fixative for immunoelectron microscopy. J Histochem Cytochem 22:1077-1083.

McLean JH, Shipley MT, Bernstein DI (1989) Golgi-like, transneuronal retrograde labelling with CNS injections of herpes simplex virus type 1. Brain Res Bull 22:867-881.

Milligan CE, Cunningham TI, Levitt $P$ (1991a) Differential immunochemical markers reveal the normal distribution of brain macrophages and microglia in the developing rat brain. J Comp Neurol 314:125-135.

Milligan CE, Levitt P, Cunningham TJ (1991b) Brain macrophages and microglia respond differently to lesions of the developing and adult visual system. J Comp Neurol 314:136-146.

Miselis RR, Lee BH, Enquist LW, Card JP (1991) Characterization of the visceral neuraxis by transneuronal passage of pseudorabies virus. Soc Neurosci Abstr 17:545.13.

Morahan PS (1983) Interactions of herpesviruses with mononuclear phagocyles. In: Immunobiology of herpes simplex virus infection (Rouse B, Lopez C, eds), pp 71-89. Boca Raton: CRC.

Morahan PS, Connor JR, Leary KR (1985) Viruses and the versatile macrophage. Br Med Bull 41:15-21.

Murray M, Wang S-D, Goldberger ME, Levitt P (1990) Modification of astrocytes in the spinal cord following dorsal root or peripheral nerve lesions. Exp Neurol 110:248-257.

Norgren RB, Lehman MN (1989) Retrograde transneuronal transport of herpes simplex virus in the retina after injection in the superior colliculus, hypothalamus and optic chiasm. Brain Res 479:374-378.

Paxinos G, Watson C (1986) The rat brain in stereotaxic coordinates, 2d ed. Orlando: Academic.

Perry VH, Hume DA, Gordon S (1985) Immunohistochemical localization of macrophages and microglia in the adult and developing mouse brain. Neuroscience 15:313-326.

Plata-Salaman CR (1990) Immunoregulators in the nervous system. Neurosci Biobehav Rev 15:185-215.

Rinaman L, Miselis RK (1987) The vagal innervation of rat pancreas as revealed by cholera toxin-horseradish peroxidase conjugate. $\mathrm{J}$ Autonom Nerv Syst 21:109-125.

Rinaman L, Milligan CE, Levitt P (1991) Persistence of Fluoro-Gold following degeneration of labeled motoneurons is due to phagocytosis by microglia and macrophages. Neuroscience 44:765-777.

Robbins AK, Ryan JP, Whealy ME, Enquist LW (1989) The gene encoding the gIII envelope protein of pseudorabies virus vaccine strain Bartha contains a mutation affecting protein localization. J Virol 63: 250-258.

Robinson AP, White TM, Mason DW (1986) Macrophage heterogeneity in the rat as delineated by two monoclonal antibodies MRC $\mathrm{OX}-41$ and MRC OX-42, the latter recognizing complement receptor type 3. Immunology 57:239-247.

Rotto-Percelay DM, Wheeler JG, Osorio FA, Platt KB, Loewy AD (1992) Transneuronal labeling of spinal interneurons and sympathetic preganglionic neurons after pseudorabies virus injections in the rat medial gastrocnemius muscle. Brain Res 574:291-306.

Rouiller EM, Capt M, Dolivo M, DeRibaupierre F (1986) Tensor tympani reflex pathways studied with retrograde horseradish peroxidase and transneuronal viral tracing techniques. Neurosci Lett 72 : 247-252.

Rouiller EM, Capt M, Dolivo M, DeRibaupierre F (1989) Neuronal organization of the stapedius reflex pathways in the rat: a retrograde HRP and viral transneuronal tracing study. Brain Res 476:21-28.

Salamat SM, Tallent MW, Keane RW (1988) The role of astrocytes in immune responses within the central nervous system. In: Neurology and neurobiology, vol 39, The biochemical pathology of astrocytes (Norenber MD, Hert L, Schousboe A, eds), pp 247-259. New York: Liss.

Sarmiento M (1988) Intrinsic resistance to viral infection. Mouse macrophage restriction of herpes simplex virus replication. J Immunol 141:2740-2748

Sarmiento M, Kleinerman ES (1990) Innate resistance to herpes simplex virus infection. Human lymphocyte and monocyte inhibition of viral replication. J Immunol 144:1942-1953.

Schwaber JS, Kapp BS, Higgins GA, Rapp RP (1982) Amygdaloid and basal forebrain direct connections with the nucleus of the solitary tract and the dorsal motor nucleus. J Neurosci 2:1424-1438.

Shapiro RE, Miselis RR (1985) The central organization of the vagus nerve innervating the stomach of the rat. J Comp Neurol 238:473488.

Sminia T, DeGroot CJA, Dijkstra CD, Koetsier JC, Polman CH (1987) Macrophages in the central nervous system of the rat. Immunobiology 174:43-50.

Sternini C, De Giorgio R, Anderson K, Enquist LW, Card JP, Rinaman L (1991) Pancreatic neuronal circuits defined by transneuronal transport of pseudorabies virus. Soc Neurosci Abstr 17:545.8.

Stevens JG (1991) Herpes simplex virus: neuroinvasiveness, neurovirulence and latency. Semin Neurosci 3:141-147.

Strack AM, Loewy AD (1990) Pseudorabies virus: a highly specific 
transneuronal cell body marker in the sympathetic nervous system. J Neurosci 10:2139-2147.

Strack AM, Sawyer WB, Hughes JH, Platt KB, Loewy AD (1989a) A general pattern of CNS innervation of the sympathetic outflow demonstrated by transneuronal pseudorabies viral infections. Brain Res 491:156-162.

Strack AM, Sawyer WB, Platt KB, Loewy AD (1989b) CNS cell groups regulating the sympathetic outflow of the adrenal gland as revealed by transneuronal cell body labeling with pseudorabies virus. Brain Res 491:274-296.

Streit WJ, Graeber MB, Kreutzberg GW (1988) Functional plasticity of microglia: a review. Glia 1:301-307.

Stroop WG, Schaefer DC (1987) Herpes simplex virus, type 1 invasion of the rabbit and mouse nervous systems revealed by in situ hybridization. Acta Neuropathol (Berl) 74:124-132.

Stroop WG, McKendall RR, Battles E-JMM, Schaefer DC, Jones B (1990) Spread of herpes simplex virus type 1 in the central nervous system during experimentally reactivated encephalitis. Microbiol Pathol 8:119-134.

Thomas EE, Lau AS, Kim SU, Osborne D, Kastrukoff LF (1991) Variation in resistance to herpes simplex virus type 1 of oligodendrocytes derived from inbred strains of mice. J Gen Virol 72:2051-2057.

Tigges MA, Koelle D, Hartog K, Sekulovich RE, Corey L, Burke L (1992) Human CD8 + herpes simplex virus-specific cytotoxic T-lymphocyte clones recognize diverse virion protein antigens. J Virol 66 : 1622-1634.

Ugolini G, Kuypers HGJM, Simmons A (1987) Retrograde transneuronal transfer of herpes simplex virus type 1 (HSV-1) from motoneurones. Brain Res 422:242-256.

Ugolini G, Kuypers HGJM, Strick PL (1989) Transneuronal transfer of herpes virus from peripheral nerves to cortex and brainstem. Scicncc 243:89-92.

Vahlne A, Nystrom B, Sandberg M, Hamberger A, Lycke E (1978) Attachment of herpes simplex virus to neurons and glial cells. J Gen Virol 40:359-371.

Vahlne A, Svennerholm B, Sandberg M, Hamberger A, Lycke E (1980) Differences in attachment between herpes simplex type 1 and type 2 viruses to neurons and glial cells. Infect Immun 28:675-680.
Weinstein DL, Walker DG, Akiyama H, McGeer PL (1990) Herpes simplex virus type 1 infection of the CNS induces major histocompatibility complex antigen expression on rat microglia. J Neurosci Res 26:55-65.

Wekerle H, Linington C, Lassmann H, Myermann R (1986) Cellular immune reactivity within the CNS. Trends Neurosci 271-277.

Whealy ME, Card JP, Meade RP, Robbins AK, Enquist LW (1991) Effect of brefeldin A on alphaherpesvirus membrane protein glycosylation and virus egress. J Virol 65:1066-1081.

Wittmann G, Rziha H-J (1989) Aujeszky's disease (pseudorabies) in pigs. In: Herpesvirus diseases of cattle, horses and pigs (Wittmann G, ed), pp 230-333. Boston: Kluwer.

Wong GHW, Clark-Lewis I, Harris AW, Schrader JW (1984) Effect of cloned interferon- $\gamma$ on expression of $\mathrm{H}-2$ and Ia antigens on cell lines of hemopoietic, lymphoid, epithelial, fibroblastic and neuronal origin. Eur J Immunol 14:52-56.

Yu-Wen L, Wesselingh SL, Blessing WW (1992) Projections from rabbit caudal medulla to $\mathrm{C} 1$ and $\mathrm{A} 5$ sympathetic premotor neurons, demonstrated with Phaseolus leucoagglutinin and herpes simplex virus. J Comp Neurol 317:379-395.

Zarling JM, Moran PA, Burke RL, Pachl C, Berman PW, Lasky LA (1986) Human cytotoxic T cell clones directed against herpes simplex virus-infected cells. IV. Recognition and activation by cloned glycoproteins $\mathrm{gB}$ and $\mathrm{gD}$. J Immunol 136:4669-4673.

Zarling JM, Moran PA, Brewer L, Ashley R, Corey L (1988) Herpes simplex virus (HSV)-specific proliferative and cytotoxic $\mathrm{T}$ cell responses in humans immunized with HSV type 2 glycoprotein subunit vaccine. J Virol 62:4481-4485.

Zemanick MC, Strick PL, Dix RD (1991) Direction of transneuronal transport of herpes simplex virus 1 in the primate motor system is strain dependent. Proc Natl Acad Sci USA 88:8048-8051.

Zsak L, Sugg N, Ben-Porat T (1992) The different interactions of a gIII mutant of pseudorabies virus with several different cell types. J Gen Virol 73:821-827.

Zuckermann FA, Zsak L, Mettenleiter TC, Ben-Porat T (1990) Pseudorabies virus glycoprotein gIII is a major antigen for murine and swine virus-specific cytotoxic T lymphocytes. J Virol 64:802-812. 